\title{
Conscious and Unconscious Perception: Experiments on Visual Masking and Word Recognition
}

\author{
ANTHONy J. MARCEL \\ MRC Applied Psychology Unit, Cambridge, England
}

Five experiments are presented which explore the relation of masking to consciousness and visual word processing. In Experiment 1 a single word or blank field was followed by a pattern mask. Subjects had to make one of three decisions: Did anything precede the mask? To which of two probe words was what preceded the mask more similar graphically? To which of two probe words was it more similar semantically? As word-mask stimulus onset asynchrony (SOA) was reduced, subjects reached chance performance on the detection, graphic, and semantic decisions in that order. In Experiment 2, subjects again had to choose which of two words was more similar either graphically or semantically to a nondetectable masked word, but the forced-choice stimuli now covaried negatively on graphic and semantic similarity. Subjects were now unable to choose selectively on each dimension, suggesting that their ability to choose in Experiment 1 was passively rather than intentionally mediated. In Experiment 3 subjects had to make manual identification responses to color patches which were either accompanied or preceded by words masked to prevent awareness. Color-congruent words facilitated reaction time (RT), color-incongruent words delayed RT. Experiment 4 used a lexical decision task where a trial consisted of the critical letter string following another not requiring a response. When both were words they were either semantically associated or not. The first letter string was either left unmasked, energy masked monoptically, or pattern masked dichoptically to prevent awareness. The effect of association was equal in the unmasked and pattern masked cases, but absent with energy masking. In Experiment 5 repeating a word-plus-mask (where the SOA precluded detection) from 1 to 20 times (a) increased the association effect on a subsequent lexical decision, but had no effect on (b) detectability or (c) the semantic relatedness of forced guesses of the masked word. It is proposed that central pattern masking has little effect on visual processing itself (while peripheral energy masking does), but affects availability of records of the results of those processes to consciousness. Perceptual processing itself is unconscious and automatically proceeds to all levels of analysis and redescription available to the perceiver. The general importance of these findings is to cast doubt on the paradigm assumption that representations yielded by perceptual analysis are identical to and directly reflected by phenomenal percepts.

Experiments 1, 3, and 4 were presented at the meeting of the Experimental Psychology Society, Stirling, Scotland in July 1974. The author thanks Paul Rajan, Howard Gibbins, Mark Lockwood, David Nicholls, and Jeanette Bye for their help in running and analyzing the experiments. Helpful discussion of the work was provided by Michael Turvey and on a previous draft of this paper by Betty Ann Levy and Earl Hunt. 


\section{INTRODUCTION}

The purpose of this paper is to reassess the role of visual pattern masking. In doing so it challenges certain aspects of recent informationprocessing approaches to perception. This paper is primarily experimental and general discussion is limited to some immediate and general implications of the findings; a further paper follows wherein a general approach to consciousness will be proposed and various phenomena will be discussed in terms of the differences between conscious and nonconscious processes. It is necessary first to set the general theoretical context of the present studies.

Scientific paradigms, in the Kuhnian sense (Kuhn, 1970) carry with them assumptions, often implicit, according to which investigations are carried out and data are interpreted. One paradigm assumption central to psychophysical and information-processing approaches to perception, which is the focus of the present paper is what will be referred to as the Identity Assumption. The representations which constitute conscious experience are assumed to be the very same ones that are derived and used in sensory and motor processes. Characteristics of intentional responses or perceptual report are often assumed to directly reflect perceptual-cognitive processing. That is, (a) representations which result from analysis or processing of an event or aspect of it and which can influence bchavior often fail to be distinguished from (b) representations which can be consciously reflected upon or reported or serve as the basis for intentional choices. Another paradigm assumption, more explicit, is that of Perceptual Microgenesis. This assumption postulates the nonimmediacy of percepts and nonunity of their aspects. In essence, the course of perceptual processing is held to be linear, sequential, and hierarchical. (Interactive models, where top-down and bottom-up processes are combined, do not in fact violate the essential logic.) Haber (1969) and Posner (1969) provide good examples of these assumptions. The linear, sequential aspect amounts to conceiving of different kinds of representations as being derived one from another in a particular structural and temporal order. The hierarchical aspect has conceived of this order either as synthetic, "higher level" information being derived from "lower level" information, or analytic, where perception proceeds from the general to the specific. These particular paradigm assumptions have had important consequences. For example, in holding to linearity and the Identity assumption, interpretations of Reicher's (1969) and Wheeler's (1970) results on the superiority of letter identification in the context of a word have proposed the analytic hierarchic notion that somehow the "wordness" of a word is processed before its component letters. Similar inferences are drawn from studics of visual scarch (Brand, 1971; Ingling, 1972) that the category of a character can be analyzed before its identity. An example of 
the synthetic hierarchic notion is the assumption that if "higher level" information is reportable or voluntarily usable, then all "lower level" information must also be. The converse of this is that a higher level of representation may be interfered with or prevented while leaving intact lower levels or earlier stages of representation. It is on this assumption that backward masking has often been used and interpreted, i.e., that if processing of a visual stimulus is sufficiently interfered with at a stage of precategorical representation, descriptions derived from that representation cannot be achieved (Haber, 1969; Sperling, 1967; Turvey, 1973). Another example of the synthetic assumption has been the interpretation of reaction time data from same-different judgments in terms of the linear hierarchy of stages (e.g., physical, name, category). This has relied upon the Identity Assumption in supposing that a subject's response can be based on a particular stage of processing uncontaminated by any further stage of processing. Indeed the "Levels of Processing" approach in the hands of Craik and Lockhart (1972) even holds explicitly that the upper limit of perceptual processing is under subjects' conscious voluntary control, insofar as they may choose to concentrate their processing at a particular stage in a synthetic hierarchy.

Recently dissatisfaction has been expressed with certain aspects of the above assumptions. Most particularly, attention has focused upon the distinction between conscious and nonconscious states and processes (Dixon, 1971; Posner \& Snyder, 1975; Shallice, 1972) and between automatic processes and those under strategic control (Anderson \& Bower, 1973; Posner \& Snyder, 1975; Shiffrin, 1975). However, the paradigm assumptions mentioned above have remained largely intact. This paper seeks to concentrate mainly on that of the Identity of perceptual processing with conscious representation and strategic control. There are several reasons to question this assumption.

First, an enormous amount of visual processing is necessarily carried out automatically and without awareness. The aspects of visual perception emphasized by Gibson $(1950,1966)$ have been largely ignored by cognitive theorists who, for the most part, have used measures based on conscious manipulation or judgment or on memory. Not only do the aspects of vision stressed by Gibson support activities such as balance, locomotion, and orientation, but might well be the basis of articulation of the visual field for object perception (Marr, 1976; Turvey, 1975; Fox, 1978). Indeed focal attention could not be guided as it is, either visually as in eyc movements, or auditorily as in attending to speech streams if unattended information was not analyzed to high levels of significance.

Second, information-processing theorists have paid little or no attention to the phenomena of "subliminal" perception. This may be partially explained by all the doubts raised as to the alternative explanations of the 
studies carried out in the 1950s directed at motivational aspects of perception (e.g., criticisms such as experimental artifacts, word-frequency effects, experimenter effects). However, this neglect is hardly justified in view of the number of replicable demonstrations of perception without awareness reviewed by Dixon (1971). Certainly in the area of selective attention many recent studies demonstrate, less problematically, that while people are unable to comment on the nature of unattended stimuli, they affect both the general state of subjects (Corteen \& Wood, 1972; von Wright, Anderson, \& Stenman, 1975) and their responses to attended stimuli (Lewis, 1970; Mackay, 1973).

Third, certain phenomena from the clinical field appear to imply that adequate perceptual and cognitive analysis may not be reflected directly by people's responses. Patients with an acquired reading impairment which has been termed Deep Dyslexia (Coltheart, Patterson, \& Marshall, 1980) make responses which are semantically, but neither phonologically nor graphemically, related to a target word presented singly and with unlimited viewing time (e.g., "buy" for debt, "swear" for curse). The same is true for another type of patient when attempting to repeat single spoken words (Goldstein, 1948; Morton, 1980). In neither case can the errors be completely explained by a word-finding problem in spontaneous speech. This suggests that words have been read or heard correctly, inasmuch as their appropriate lexical or semantic representations have been accessed, but that the patients are unable to recover their identity in their responses.

Interpretations of experiments in the information processing framework have largely rested upon the lack of a distinction between perceptual processing and the ability to voluntarily utilize the results of that processing or verbalize about it. The phenomena mentioned above illustrate a dissociation between the two. Perhaps the most dramatic illustrations are cases of "Blindsight." The patient reported by Weiskrantz, Warrington, Sanders, and Marshall (1974) was blind in part of the visual field due to a lesion in one occipital lobe, i.e., he was not aware of any stimulus. Yet in the hemianopic field, when forced to, he could reliably make certain shape discriminations and reach accurately for small light sources. The patient denied seeing anything and claimed he was guessing. Apart from the implications for the dissociation of conscious awareness, the phenomenon has been interpreted in terms of the two visual systems hypothesis (Humphrey, 1972), which is an instance of distributed as opposed to linear processing of different aspects of visual stimuli.

\section{An Initial Observation}

Some years ago the present author was conducting some investigations of reading in children and adults. One experiment (Marcel, Katz, \& 
Smith, 1974) consisted of single words being briefly exposed followed by a pattern mask. The subjects' task was to report whatever words or letters they were able to. A small but significant proportion of erroneous word responses, while showing little graphic or phonological relation to the stimulus, bore a striking semantic relationship to it. Thus green led to responses such as "blue" and "yellow," queen to "king," apple to "orange," light to "dark," happy to "joy," clock to "time," chair to "table." These responses are noteworthy for several reasons. First, there was little delay before a response, and therefore it is hard to argue that it is the result of some memory effect. Second, there was no semantic context to bias responses. Third, in reporting from tachistoscopic presentations subjects are usually reluctant to violate in their response any phenomenal visual impressions that they have. That is, subjects either report letters or try to generate words which conform to partial graphic or orthographic information.

Thus, unless it was purely by chance, the subjects appeared to be exhibiting some knowledge of the stimulus at a lexical or semantic level without being able to report any other characteristics of the word giving rise to such knowledge. Unfortunately, Ellis and Marshall's (1978) criticism of Allport's (1977) paper, which actually arose from the experiments reported here, suggests that some or all of these responses may well have been on a chance basis. In Allport's study, semantic errors similar to those in the Marcel, Katz, and Smith data, were found in the responses to pattern-masked words. Ellis and Marshall estimated the proportion of randomly paired stimuli and responses from Allport's data that are seen as semantically similar by judges and found that the proportion actually obtained by Allport fell within those limits. The same procedure as Ellis and Marshall's was threrefore used (Marcel, 1980a) to estimate the validity of the semantic errors in the Marcel, Katz, and Smith study. The mean chance estimate for semantically related errors for that stimulus and response sample was found to be $3.4 \%$. The actual proportion of semantic errors found in the original experiment, discounting derivational and graphically similar errors ("grass" for green, "long" for large) was $6.43 \%$ of whole-word error responses. Even allowing for some conservatism, the obtained proportion is considerably higher than the chance estimate, which leads one to believe that at least some of the semantic errors were genuine.

This observation of the independence of the availability of a word's meaning and its identity or physical characteristics was reminiscent of at least two other sets of phenomena mentioned so far. One is the paraphasias and paralexias noted in acquired aphasia and dyslexia and discussed by Goldstein (1948), Werner (1956), and Marshall and Newcombe (1973). The other is the recent literature on perception without 
awareness (Dixon, 1971). One study in the latter domain which seemed particularly pertinent was reported by Wickens (1972). He presented subjects with a word for $50,60,70$, or $80 \mathrm{msec}$ followed by a broken-letter mask for $1.5 \mathrm{sec}$. Subjects were then presented with a word for $5.0 \mathrm{sec}$ which they had to judge as similar or not to the "unseen" word. Similarity was defined on poles of Semantic Differential dimensions. On two of these dimensions, subjects performed above chance while being apparently unable to report the first word.

Wickens' method seemed to promise an experimental grasp on the phenomenon. However, his experiment is subject to at least two criticisms. First, when backward pattern masking is employed there is a wide interindividual variance in the critical interstimulus interval, or word-mask stimulus onset asynchrony (SOA). Examination of the literature cited by Turvey (1973) shows a range much wider than Wickens' $50-80 \mathrm{msec}$. Therefore some individuals may have had a different quality of information from others. Second, the fact that the subject cannot report a word does not indicate that sufficient visual information has not been analyzed. There may well be an influence of response criterion. As a matter of fact, Wickens gives no indication whether or not subjects could report the first word or any part of it. He merely states that the exposure duration was "typically too short to result in target identification."

The initial serendipitous observation and Wickens' experiment are potentially of great significance. The currently held interpretation of masking (Sperling, 1967; Turvey, 1973) is that it disrupts a relatively raw representation of visual input (iconic memory), without which input cannot be processed to achieve semantic or phonological coding. If report is impossible due to masking then it is supposedly because the icon has been interrupted and semantic features of the stimulus should not be represented. It is thus of considerable importance to establish the validity of Wickens' findings. The first experiment was an attempt to investigate the phenomenon more closely, specifically to examine subjects' knowledge of visual and semantic features of the stimulus with respect to its detectability as masking is made more severe.

\section{EXPERIMENT 1}

The object of the first study was to obtain comparative estimates of the availability and usability of three aspects of word stimuli over a range of stimulus-mask onset asynchronies. The three aspects were presence vs absence, graphic characteristics, and semantic characteristics. The reason these three aspects were chosen was that there is a necessary logical order to their processing according to most approaches to perceptual microgenesis. However, if processing is dissociated from the recovery of information in responses it is an open issue as to the relative effect of 
masking on the latter aspect at critical target-mask onset asynchronies. The method adopted was to require judgments of presence or of the graphic or semantic similarity of succeeding stimuli to the test stimulus.

\section{Method}

Subjects. The subjects were 24 undergraduates at the University of Sussex.

Stimulus materials. The stimuli were 240 words selected from the stimulus terms in two sets of word association norms (Bousfield, Cohen, Whitmarsh, \& Kincaid, 1961; Postman \& Keppel, 1970). The words ranged from four to eight letters in length. The words were used for both the Graphic and Semantic similarity conditions. Half of them were used in the presence-absence condition.

For the purposes of Graphic Similarity judgments, a pair of words was chosen to be judged against each of the stimulus words selected from the above-mentioned norms. Neither word appeared in the norms as an associate of the stimulus word. The words were chosen so that one had a high rating of graphic similarity, the other a low rating. For this, Weber's Index of Graphic Similarity (Weber, 1970) was used with one modification. Since the words were presented in lower case, graphic similarity was felt to include word shape. The nearest approximation to this was to include a score for ascenders $(h, t)$ and descenders $(g, p) .{ }^{1}$ Low graphic similarity was counted as beneath 60 , high was counted as above 200 .

For the purposes of Semantic Similarity judgments, another pair of words was chosen for each of the stimuli. One of these was the primary associate given in the association norms. The second was a word equated with the associate for graphic similarity $( \pm 50)$, which was not associated in any obvious manner with the stimulus word. For the two sets of word pairs, three independent judges were unanimous in each choice of a word on the basis of its graphic and semantic similarity to the stimulus word.

Each word was drawn in black ink in the center of a white 6 by 4 -in. card using a UNO lower case stencil, No. 2.101. Letters measured approximately 0.1 by $0.1 \mathrm{in}$. The words subtended from 1.6 to 3.4 degrees of visual angle when viewed in an Electronic Developments 3-Field Tachistoscope. The word-pair choices were presented one on top of the other. Half had the "correct" word on top, half beneath. One hundred cards had the words "present" above "absent," 100 vice versa.

In addition there was a fixation point and a mask field. The fixation point was a black disc subtending just under 0.2 degrees. The mask field was composed of parts of letters from the same stencil, printed in random orientations, over an area of $2.5 \mathrm{in}$. wide by $0.5 \mathrm{in}$. high.

\section{Procedure}

The first part of a session was concerned with finding the approximate stimulus onset asynchrony between word and mask (SOA) at which the subject began to have difficulty in deciding whether or not a word had appeared. This consisted of a crude "hunting" in which only presence-absence judgments were required. A trial consisted of the following sequence (i) the central fixation point lasting $500 \mathrm{msec}$, (ii) a word or blank field for a variable duration, (iii) the mask field lasting $500 \mathrm{msec}$. The experimenter informed the subject that on $50 \%$ of trials a word would be presented, on $50 \%$ a blank card. When a SOA was found where the subject first made errors of detection the experimental trials were begun.

The SOAs used ranged from $5 \mathrm{msec}$ above the point where the subject first showed any

' For ascenders and descenders, the term $+z$ was added to Weber's formula, where $z$ is calculated by counting 2 for each ascender/descender in equivalent $( \pm 1)$ positions from the beginning of the word and subtracting 2 each time an ascender/descender appears in a position more than two letters away from where one exists in the stimulus word. 
difficulty in detection to $20 \mathrm{msec}$ below that. Six SOAs were used differing by $5 \mathrm{msec}$ each. Thus each subject was tested over a range of $25 \mathrm{msec}$. At each SOA 120 trials were given, 40 for each of the 3 decisions. Before the experimental trials the experimenter explained the three kinds of decision required, ensuring that the subject could make each of them. It was also explained that the decisions would be required in random order.

Before each trial the experimenter said either "presence," "graphic," or "meaning" to indicate the judgment required. He then initiated the trial. Trials were the same as the preexperimental trials except that after the mask the experimenter repeated the type of judgment required and exposed a card with the two appropriate choice words on it for $5 \mathrm{sec}$. The subject was allowed a further $2 \mathrm{sec}$ to make a choice, at which point the next trial was started.

\section{Results}

The aspect of the results of essential interest is the relation between performance on the three different types of decision as a function of SOA. However, two other points must be noted. First, the SOAs at which performance on the detection and graphic judgments falls off differs widely for different individuals. The SOA at which subjects' performance on detection fell beneath $60 \%$ correct ranged from $110 \mathrm{msec}$ down to 20 msec.

Second, of great importance in evaluating this type of experiment is the fact that a number of subjects were "lost" from the sample. Three subjects refused to continue making judgments of graphic and semantic similarity at the SOAs around which they were making between $60 \%$ and $70 \%$ correct detection choices. These subjects said in essence that they did not feel able or it did not make sense to judge the qualities of something that did not exist or had not been seen. A further four subjects were treated separately for the following reason. After the session had been concluded every subject was asked to comment how he or she had carried out the task. Four subjects reported that they had felt the task to be nonsensical once they could not be sure of whether a stimulus was present, but had continued with the similarity judgments by adopting some idiosyncratic strategy. For example, one subject commented that she had judged the similarity to the first word free-associated to the end of the experimenter's pretrial cue. These subjects will be termed strategy subjects. The remaining subjects mostly reported that they had at first been uncomfortable in judging similarity when they had to guess presence or absence, but had adopted a "passive" attitude and chosen that word which "felt" right. These subjects will be termed passive subjects. The results of the 17 passive subjects and 4 strategy subjects were plotted separately. The means of the two post hoc groups of subjects are shown in Fig. 1.

Since individual subjects had to be tested at different absolute SOAs, performance is shown over the range which started from all subjects' highest SOA. 


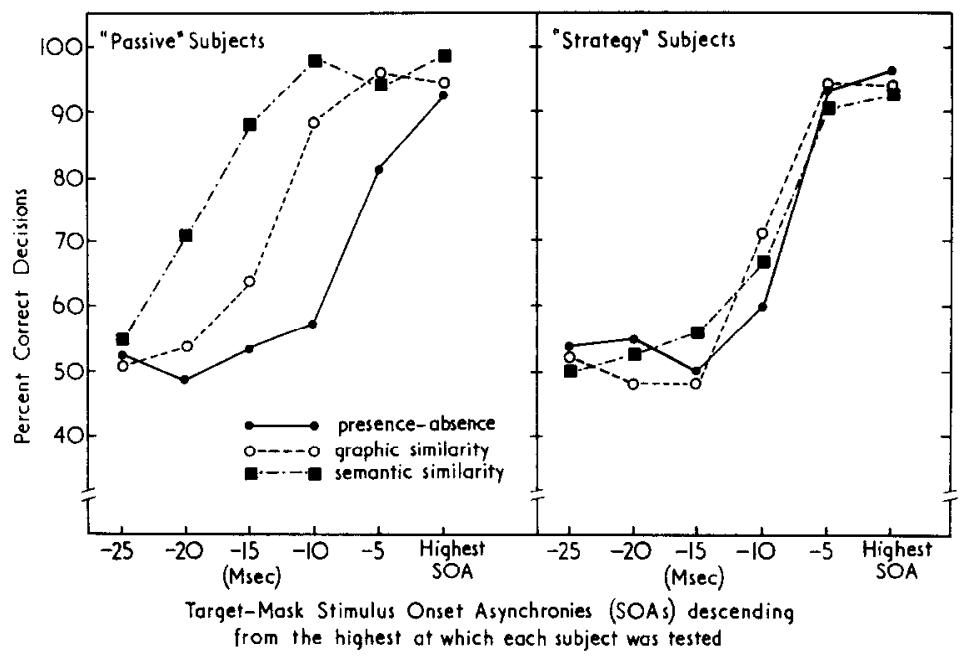

FIG. 1. Ability of "passive" and "strategy" subjects to make threc types of decision about the masked word as Target-Mask Onset Asynchrony is reduced beneath the first value producing detection errors.

There are two ways to approach the data. First, do the different types of judgment behave differently with respect to SOA? Second, can the different types of judgment be dissociated, in the sense that when one decision can no longer be made with greater than chance accuracy, another can? This involves the difficult choice of an arbitrary boundary for chance performance. This second question was dealt with in the following manner. For each subject the SOA at which performance on detection fell below $60 \%$ accuracy was determined. His performance at this point was then compared with his performance on graphic similarity at the same SOA by means of a $2 \times 2$ chi square. The same was done for each subject to compare detection with semantic similarity judgments. The results of this were that for every subject in the Passive group performance was significantly better on graphic and semantic judgments than on detection for the SOA where detection first fell below 60\% $(p<.01$ for all 17 subjects, one tailed). No subject showed this effect in the strategy group. The same procedure was followed for each subject to compare graphic and semantic judgments. That is, for the first SOA where graphic performance fell beneath $60 \%, 2 \times 2$ chi squares were performed on graphic and semantic judgments. Of the 17 passive subjects, three showed no significant difference $(p>.1)$, eight showed significantly better semantic judgments with $p<.01$, and six with $p<.001$. None of the strategy subjects showed differential semantic and graphic performance.

With regard to the strategy subjects, there is no evidence that they can 
perform differentially according to SOA on the different types of decision. However, all the other subjects show the same, rather different, pattern of results. As SOA is reduced, detection judgments suffer first, graphic similarity judgments fall next, and semantic judgments fall last. When SOAs are reduced to the level at which subjects no longer have sufficient information accessible on which to consistently base judgments of presence, graphic and semantic judgments can still be made correctly on between 80 and $100 \%$ of trials. When further SOA reduction impairs graphic decisions to between 60 and $70 \%$, semantic decisions can still be made on more than $80 \%$ of trials. This pattern was true of all the subjects who were classified as "passive."

These results qualify Wickens' supposedly implicit assumption that when subjects could not report a presented word, visual information was not available. In fact enough visual information is represented to influence a graphic choice between two further stimuli. However, the results bear out and add to his conclusion that semantic information was available when visual information was not.

The results merit comment on at least two levels. First, the sort of procedure used here and by Wickens suffers from a basic fault. It is unreasonable to ask subjects to base consciously a response on information of whose presence they are unaware. Far more sensible is to explore the influence of a stimulus on various aspects of a different task which is the main concern of the subject. This in fact is what was done in the rest of the experiments reported here. However, the method employed here at least gives a technique by which appropriate SOAs can be determined.

Second, it appears that the information about an event that has been processed (such that it is represented in the system and can influence a subsequent response or judgment) is not reflected by what a person can report of that event. This assertion is by no means novel. It has been extensively explored in the literature reviewed by Dixon (1971). However, as noted above, such a distinction has been largely ignored in development of information-processing models in recent years. Visual masking has been used on the assumption that a higher level of representation may be interfered with or prevented while leaving intact lower levels (Haber, 1969; Turvey, 1973). In the present experiment the mask appears to interfere according to the briefness of the SOA in the reverse order to that which would be expected from current information-processing accounts. Thus whatever pattern masking is doing, it does not seem to prevent per $s e$ that visual analysis which produces a representation sufficient to support graphemic access and lexical or semantic interpretation. It seems rather to affect the intentional recovery of that information. Further discussion of this issue is left until the remaining experiments have been reported since they are particularly relevant to visual masking.

However, if the intentional recovery of information was prevented by 
masking, this raises the question of how passive subjects carried out the task. Two kinds of possibility present themselves. One is that their passivity consisted in refraining from imposing an intentional strategy and that this allowed them access to information which would otherwise be "blocked." According to this view one must suppose that one can be selectively sensitive to semantic, graphic, and presence information (a) without being aware of the sensory stimulus, and (b) independently of one another. Otherwise the question asked on each trial could not have been answered appropriately. The other possibility is that when presence judgments were precluded, subjects were not responding on the basis of graphic and semantic characteristics of the masked word to which they were selectively sensitive, but were responding rather to the forcedchoice alternatives. To clarify this, suppose that automatic graphic and semantic processing of the masked stimulus each leaves residual activation. This activation might either facilitate the processing of the choice stimulus most similar to the original stimulus or enhance any activation produced by that choice stimulus on the relevant dimension. If the choice stimulus which yields the greatest activation draws an orientation response to itself, the subject might then choose that stimulus to which his or her attention is most drawn. Recall that, because of the experimental design, on trials requiring a graphic similarity choice the alternatives were both equally and sufficiently distant semantically such that semantic activation from them would not interact with that from the masked word; i.e., the masked word would not have associatively primed the semantic representations of either choice word. However, one stimulus shared a sufficient number of graphic characteristics with the masked word to have received priming from presentation of the latter. The equivalent (in reverse) was true of the choice stimuli on trials requiring a semantic similarity choice. Thus, quite spuriously, the "correct" stimulus would yield the most activation on the appropriate dimension since that dimension had already been primed, although the subject would not be aware of which characteristic was producing the activation. Therefore, if we suppose that differential activation produced an orienting response, subjects would have carried out the apparently intentional task of making independent graphic and semantic judgments by choosing the choice stimulus which most elicited an orienting response.

If this latter hypothesis is true it crucially affects the interpretation of Experiment I. Indeed the Orienting-Response explanation would increase the validity of the interpretation of the experiment in terms of nonconscious processing; the Selective Intentional hypothesis would leave open the possibility that in some sense passive subjects were conscious of aspects of the masked stimuli but their presence judgments reflected a response criterion. For these reasons Experiment II was undertaken to test between the two interpretations. 


\section{EXPERIMENT 2}

In Experiment 1 a subset of subjects appeared to be able to make independent judgments of graphic and semantic similarity to masked words whose presence they could not detect. Two hypotheses were advanced to account for their performance. The Selective Intentional hypothesis supposes that subjects were doing what they were asked to do, judging the graphic or semantic similarity of choice words to the masked word. According to this view, subjects can maintain a selective sensitivity to graphic and semantic characteristics derived from the masked stimulus, and make their judgment on that basis. The Orienting Response hypothesis proposes that the similarity choice was made on the basis of a passive orienting response to one of the forced-choice stimuli. This orienting response is putatively produced by differential activation on the relevant dimension, resulting from residual activation from the masked stimulus interacting with activation from each of the choice stimuli. Since neither of the choice stimuli were similar on the irrelevant dimension, only residual activation on the dimension being tested could interact differentially with that from the choice stimuli.

One way to test the hypotheses is to present forced-choice stimuli which within a pair covary negatively on each of the dimensions to be tested. That is, one word would be more semantically related and the other more visually related to the masked stimulus. According to the Selective Intentional hypothesis, consistent selective judgments should still be possible. The Orienting Response hypothesis predicts they should not be possible. Either (a) the choice would be determined by whichever stimulus provides greater differential cumulative activation on that trial, or (b) there will be an overall bias toward choice stimuli which are more similar on one dimension, if one of the dimensions takes precedence for any reason. These predictions as stated do not depend on a common or even comparable scale of graphic and semantic similarity, since the selective hypothesis supposes selective attention to a dimension and the orienting response hypothesis embraces in its predictions any difference in similarity scaling.

\section{Method}

Subjects. The most important aspect of the experiment was to use "passive" subjects. To achieve this, 12 of the passive subjects from Experiment 1 were used. Three of the 17 had not exhibited significant superiority of semantic over graphic judgments when the latter fell beneath $60 \%$; two subjects were unavailable. Four more subjects were chosen by running them on a partial replication of Experiment 1 (the first two SOAs beneath that where mistakes on presence judgments were first made) and asking for reports of what they had done. The first four subjects satisfying this criterion were accepted, three having to be 
rejected on the basis of subjective report of strategy and lack of a difference between presence judgments and graphic and semantic similarity judgments. The sixteen subjects were all undergraduates at the University of Sussex.

Stimuli. All stimuli were printed in lower case using the same stencil as in Experiment 1. The test stimuli were generated as follows. Twenty words were selected as targets to exhibit a good range of meaning and graphic form. Semantically similar words were generated by selecting synonyms or same-category exemplars from free associates to the targets. Graphically related words were generated by changing letters to maintain word shape. Two restrictions were imposed. First, graphically similar words scored highly, or much higher than semantically similar words, on Weber's (1970) Index of Graphic Similarity, while semantically similar words scored as low as possible. This meant that some semantically similar words were not the most primary of associates. Second, graphically similar words were not semantically similar. This was a matter of subjective judgment. In one or two cases, graphically similar words were probably similar connotatively (rather than denotatively) to their target word (e.g., blood-flood). These stimuli are listed with scores on the Graphic Similarity Index in Table 1.

Forced-choice stimuli were made for each target by printing on $6 \times 4$-in. cards its graphically and semantically similar counterparts one above the other. Two different sets of cards were made, which were the reverse of one another with respect to which word was above and which below.

Each subject was tested with 20 choice cards with the graphic and semantic counterparts of the target (G/S). Half of each set of cards was used for a graphic similarity judgment and

TABLE 1

Stimuli Used in Experiment 2

\begin{tabular}{llclc}
\hline \multicolumn{1}{c}{ Target } & $\begin{array}{c}\text { Graphically } \\
\text { sinnilar }\end{array}$ & $\begin{array}{c}\text { Graphic } \\
\text { similarity }\end{array}$ & $\begin{array}{c}\text { Semantically } \\
\text { similar }\end{array}$ & $\begin{array}{c}\text { Graphic } \\
\text { similarity }\end{array}$ \\
\hline acquaintance & acquiescence & 775 & friend & 45 \\
addition & ambition & 900 & maths & 62 \\
alarm & alien & 740 & warning & 143 \\
blood & flood & 760 & flesh & 70 \\
frame & franc & 580 & edging & 42 \\
gay & bay & 463 & llappy & 260 \\
hint & hind & 645 & clue & 50 \\
inform & improve & 437 & tell & 33 \\
lamp & land & 475 & light & 330 \\
load & loan & 645 & cargo & 80 \\
moral & molar & 640 & ethical & 332 \\
pole & gate & 255 & stick & 40 \\
request & respect & 714 & ask & 21 \\
rear & roar & 633 & back & 50 \\
rope & rage & 550 & string & 60 \\
sheep & cheer & 370 & goat & 40 \\
source & course & 463 & origin & 80 \\
throat & throne & 637 & neck & 33 \\
track & trace & 700 & path & 84 \\
wine & wing & 645 & drink & 156 \\
\hline
\end{tabular}


half for a semantic similarity judgment. Which judgment condition each target word was submitted to was balanced over subjects, as was order of presentation.

Stimuli and a pattern mask were printed as in Experiment 1.

Apparatus. An Electronic Developments 3-Field Tachistoscope was used.

Procedure. A threshold was determined for each subject with the stimuli used for that purpose in Experiment 1. The SOA was found where errors were first made on presence-absence judgments and an SOA $10 \mathrm{msec}$ beneath that was used for testing. Note that just one SOA value was used for testing. A test trial consisted of the following sequence (i) a central fixation point lasting $500 \mathrm{msec}$, (ii) the target word lasting for the appropriate duration, (iii) the pattern mask lasting $500 \mathrm{msec}$, (iv) the experimenter showed a card to the subject with the two choice words on it. Ten seconds were allowed for the choice. Subjects were instructed on each trial whether to make a Graphic or a Semantic choice. They were told the choice to be made before each trial and again when the alternatives were presented.

\section{Results and Discussion}

The results are shown in Table 2. Differential behavior was clearly impossible. While on graphic judgments all subjects chose the graphically similar alternative more frequently, except Subjects 11 and 12 who showed no consistent bias, on semantic judgments only Subjects 10, 11, and 16 showed any bias to choosing the semantically more similar alternatives. Moreover, on semantic judgments all subjects except 8, 10, 11, and 16 actually chose the graphically more similar alternative. While per-

\section{TABLE 2}

Individual Subjects' Choices in Graphic and Semantic Similarity Judgments between Pairs of Graphically (G) and Semantically (S) Similar Alternatives

\begin{tabular}{|c|c|c|c|c|}
\hline Subject & $\begin{array}{c}\text { Similarity } \\
\text { judgment: } \\
\text { Stimulus } \\
\text { chosen: }\end{array}$ & $\begin{array}{c}G \\
G: S\end{array}$ & $\begin{array}{c}S \\
G: S\end{array}$ & $\begin{array}{c}\text { Test SOA } \\
\text { detection } \\
\text { "threshold" } \\
\text { less } 10 \mathrm{msec}\end{array}$ \\
\hline 1 & & 9:1 & $8: 2$ & 20 \\
\hline 2 & & $7: 3$ & $6: 4$ & 15 \\
\hline 3 & & $6: 4$ & $6: 4$ & 20 \\
\hline 4 & & 9:1 & $9: 1$ & 25 \\
\hline 5 & & $8: 2$ & $7: 3$ & 15 \\
\hline 6 & & $6: 4$ & $7: 3$ & 10 \\
\hline 7 & & $7: 3$ & $10: 0$ & 5 \\
\hline 8 & & $8: 2$ & $5: 5$ & 30 \\
\hline 9 & & $9: 1$ & $9: 1$ & 25 \\
\hline 10 & & $7: 3$ & $4: 6$ & 30 \\
\hline 11 & & $5: 5$ & $3: 7$ & 20 \\
\hline 12 & & $5: 5$ & $6: 4$ & 20 \\
\hline 13 & & $10: 0$ & $6: 4$ & 45 \\
\hline 14 & & $6: 4$ & $5: 5$ & 25 \\
\hline 15 & & $8: 2$ & $9: 1$ & 10 \\
\hline 16 & & $8: 2$ & $3: 7$ & 15 \\
\hline
\end{tabular}


formance on graphic judgments supports the intentional retrieval hypothesis, that on semantic judgments does not. Taken together performance on the two kinds of judgment suggest either that only graphic information is available or that a passive process is responsible, where graphic activation is predominant. That is, instructions had no effect on the stimulus chosen.

Experiment 2 thus appears to favor an orientation response interpretation of Experiment 1. In attempting to make deliberate judgments based on information of whose external source one is unaware, it would seem that one makes use of the relevant nonconscious information, if it is available, by relying passively on its effects (e.g., upon attention) rather than being able selectively to retrieve it or be sensitive to it such that it can be the basis of an intentional choice. Of course this may only be true when one is able to rely on such effects, that is, when alternative stimuli are presented. But at the moment there is no good evidence that one can deliberately retrieve such information in spontaneous report or comment.

One further point merits comment. There appeared to be a predominance in Experiment 2 of graphic information. Yet in Experiment 1, performance was better on semantic judgments. First, the bias in the second experiment in no way means that semantic information was not represented. Second, the situation in the two experiments was different, that in Experiment 1 favoring the manifestation of such information (i.e., the low and controlled graphic similarity of the choice on semantic judgment trials). Indeed the results of the two experiments taken together suggest that graphic information dominates scmantic information when both are present, but if one can tap them independently semantic information is more reliable and less transient in the sense of its resistance to pattern masking. Of course these sorts of general statements rely on an assumed equivalence of scaling of graphic and semantic similarity in the present experiments. In a series of studies based on the present ones, Fowler, Wolford, Slade, and Tassinary (1981) have gathered data that suggest that the relative efficacy of graphic and semantic similarity judgments under severe pattern masking indeed depends on how similar the choice alternatives are to the masked stimulus. Whether such a scaling factor interacts with the transience of different types of information, in terms of the effects of SOA reduction, remains to be seen. However, the very fact that the same subjects who showed appropriate judgments in Experiment 1 could not do so in Experiment 2 suggests that their performance in Experiment 1 was not artifactual.

\section{EXPERIMENT 3}

Experiment 3 was motivated on two grounds. It was pointed out above that direct addressing of an unconscious representation may yield less 
information about processing than indirect addressing. That is, asking a subject to comment on or base a judgment on an inaccessible representation is phenomenally bizarre and may well induce the use of strategies which either disguise or eliminate the effects of that representation. It is far better to test the presence of information by its effect on a primary task. A "Stroop" situation is ideal for this purpose, where a response based on color is affected by the presence of differentially related words. The situation is especially apposite since it is with regard to Stroop effects that Keele (1972) has argued that lexical access makes no demands on attention and does not draw on limited capacity mechanisms. Most importantly, Stroop-type interference by irrelevant words demonstrates lexical access at the least. If words that have been pattern masked such that they can not even be detected, affect responses based on colors in a way related to semantic relationships, then theoretical inferences regarding semantic as opposed to merely lexical access are more justified than Experiment 1 permits.

The second motivational context for Experiment 3 is that certain accounts of interference by irrelevant words with color naming or sorting place such interference at the level of response production. Specifically, Morton and Chambers (1973) propose that the name of the word enters a response buffer faster than that of the color. Morton and Chambers' proposal is based on the intuitively plausible notion that speed of deriving a verbal response to word stimuli is faster than to nonword stimuli, and that for the skilled reader it is automatic. Other proposals (e.g., Seymour, 1975 ) suggest that interactive effects may occur at earlier stages.

One way of testing this is to utilize the effects shown in Experiment 1. Thus, under certain conditions of pattern masking, while a verbal naming response to a word cannot be generated, semantic characteristics appear to be represented. Hopefully, by requiring manual rather than verbal responses, one can reduce the probability of effects at a stage of lexical production. Thus the purpose of Experiment 2 was to compare the effects of undetected masked words with those of readable words on manual responses to color patches.

\section{Method}

Subjects. The subjects were six right-handed undergraduates at Sussex University. All subjects had normal color vision according to the Ishihara test.

Stimuli. The color stimuli were squares 1.5 by 1.5 in. centered on 6 by 4 -in. white cards. For the experimental triais these were red, blue, green, and yellow. A brown color square was used for the threshold adjustment described below.

Word stimuli were typed in the center of white cards 6 by 4 in. There were four color names: red, blue, green, and yellow. There were also three cards with supposedly neutral words on them. These were "cough," "kind," and "water." There was also a blank card with nothing on it. The words were $0.1 \mathrm{in}$. high and a maximum of $0.6 \mathrm{in}$. wide. A pattern 
mask was constructed by typing letters in the same typeface in random orientations in the center of a card. The pattern mask was $0.5 \mathrm{in}$. high by 1.0 in wide. The stimuli were exposed in an Electronic Developments 3-Field Tachistoscope. The luminances of the three fields were equalized using an S.E.I. Spot Photometer at $\mathbf{4 4 . 6}$ footlamberts. The rough spatial arrangement of stimuli is shown in Fig. 2(a).

\section{Procedure}

Before any experimental sessions the SOA was determined for each subject at which they were unable to make presence-absence judgments of a word or blank field before the pattern mask. The same procedure was used as in Experiment 1 with some exceptions. The words were typed in the same typeface as the experimental words and the typed pattern mask was used. The brown color patch was exposed simultaneously throughout. The graphic and semantic similarity judgments were not required. The critical SOA to be found was the highest at which subjects could not perform above $60 \%$ correct. The SOA used for the experimental sessions was $5 \mathrm{msec}$ beneath that. Experimental SOAs ranged from 30 to $80 \mathrm{msec}$.

There were four different experimental conditions tested on different sessions. These were produced by the combination of the two following factors (a) Word-Color Asynchrony: either the onset of the word and color patch were simultaneous or the word onset was 400 msec before that of the color; (b) Word-Mask Asynchrony: either the mask followed the word after $400 \mathrm{msec}$, which in all cases allowed subjects to name the word, or the SOA was that determined as described above. These two conditions will be described as Suprathreshold and Subthreshold.

The subjects' task was to press as fast as possible one of four buttons corresponding to each of the color patches. These buttons were beneath the middle and index fingers of the two hands. The correspondence between stimulus and response was indicated by saying "this button goes with this color" to avoid unnecessary naming. Different stimulus-response correspondences (i.e., different spatial response mappings) were used for each subject.

The sequence of a trial is shown in Fig. 2(b). No fixation point was used, but the subject was asked to fixate the center of the screen when the experimenter said "Ready." The sequence was then initiated by the experimenter who pressed a button which clicked audibly. After $1 \mathrm{sec}$ the word field came on and the color patch came on cither simultancously or $400 \mathrm{msec}$ after. The mask replaced the word either after $400 \mathrm{msec}$ or at the predetermined SOA. The mask and color patch stayed on until the subject's response. In the asynchronous conditions, subjects were instructed to use the first field (word or blank) as a temporal cue for the color in the suprathreshold sessions, and to use the mask as a temporal cue in the subthreshold sessions. These sessions were given in a different random order to each subject.

Within each session there were four different types of trial according to the relation of the word to the color: (a) Color Congruent, where the word was the name of the color; (b) Color Incongruent, where the word was the name of one of the other colors; (c) Neutral, where the word was one of the noncolor words; (d) No Word, where the blank card was exposed. For each type of word-color combination, each color patch was exposed six times (twice with each of the three possible stimuli in (b) and (c) and six times with the same stimuli in (a) and (d) to equalize number of trials). There were thus 96 experimental trials in all. Errors were noted and those trials were rerun once each at the end of the session. Other than those trials the order of trials was random. About $5 \mathrm{sec}$ elapsed between trials.

Before each experimental session 90 practice trials were given. The first 50 were without any words presented. In the case of suprathreshold sessions, the next 40 trials were given with words; in the case of subthreshold sessions, the next 40 trials were given with the blank card followed by the mask at that subject's predetermined SOA. On the 
(a)

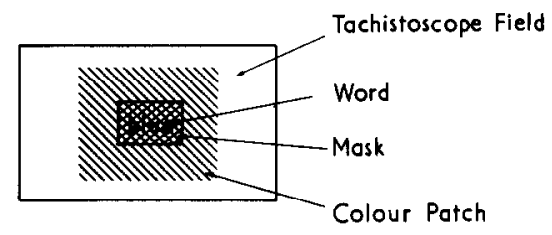

(b)

AWARENESS
OF WORD

$\begin{array}{ll}\text { Aware } & \begin{array}{l}\text { Word } \\ \text { Mask } \\ \text { Colour } \\ \text { Response }\end{array} \\ & \text { Word } \\ & \text { Mask } \\ \text { Unawore } & \text { Colour } \\ & \text { Response }\end{array}$

Word-Colour SOA=Omsec

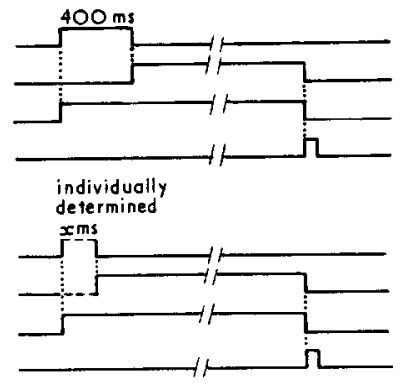

Word-Colour SOA $=400 \mathrm{msec}$

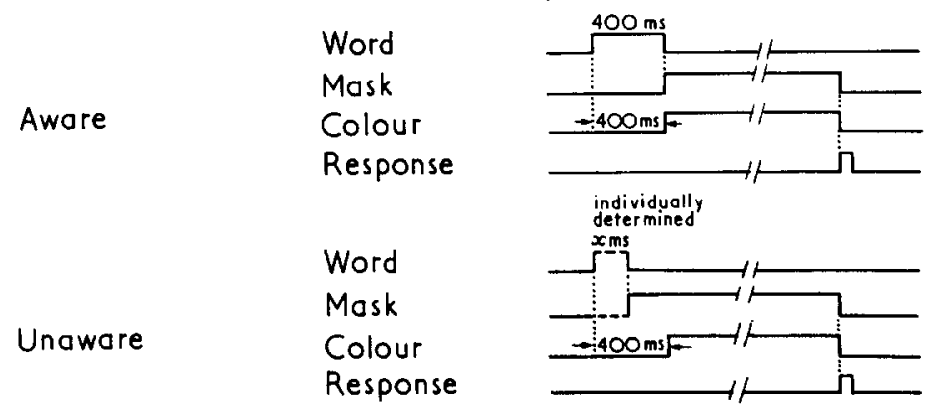

FIG. 2. (a) Spatial arrangement of stimulus events in color identification task. (b) Temporal arrangement of events in different conditions of color identification task.

subthreshold sessions 40 detection trials were run at the predetermined SOA at the beginning of the session and immediately after the experimental trials. No changes in the direction of better detection performance were found.

\section{Results}

When questioned after all the sessions no subject reported having been aware of the presence of words in the subthreshold sessions. Five of the 
six subjects said that they assumed that those sessions were control conditions without words.

Table 3(a) shows the mean absolute reaction times for each word condition under each of the SOA conditions. In Table 3(b), the RTs in the No Word condition are taken as a baseline level and the mean differences in RT between that and the other conditions are given.

An overall five-way analysis of variance was performed with factors: Word Typc, Color, Sub- vs Suprathreshold, Word-Color SOA, and Subjects. The overall main effect of Word Type was significant $(F(3,5)=$ $32.84, p<.001)$, as was Sub- vs Suprathreshold $(F(9,45)=8.07, p<.05)$, and Word-Color SOA $(F(1,5)=12.24, .01<p<.025)$. The only other significant effects were the interactions between Word Type and Color $(F$ $(9,45)=2.24, p<.05)$ and between Word Type and Word-Color SOA $(F$ $(3,15)=4.85, .01<p<.025)$. Further separate analyses for Sub- and Suprathreshold conditions showed that the effect of Word Type was significant in both (Sub: $F(3,15)=18.88, p<.001$; Supra: $F(3,15)=23.24$, $p<.001)$. Also while the SOA $\times$ Word Type interaction was significant Suprathreshold $(F(3,15)=8.03, p<.01)$, it was not significant Subthreshold $(F(3,15)=2.64)$. Newman-Keuls multiple comparisons revealed that in all Word-Color SOA and threshold conditions, while there was no difference between No Word and Neutral Words, Color-Congruent and Incongruent Words significantly facilitated and impeded reaction time. Table 4 shows the mean errors for word type under the four SOA conditions. There was no significant effect except for the

TABLE 3

Reaction Time to Color under Various Conditions

\begin{tabular}{lcccc}
\hline \multicolumn{1}{c}{ Word stimulus: } & No Word & Neutral & Congruent & Incongruent \\
\hline \multicolumn{4}{c}{ (a) Mean correct choice } \\
\hline
\end{tabular}


TABLE 4

Mean Errors under Different Masking and Word Conditions

\begin{tabular}{|c|c|c|c|c|c|}
\hline Word stimulus: & No Word & Neutral & Congruent & Incongruent & $\begin{array}{l}\text { Total } \\
\text { errors }\end{array}$ \\
\hline \multicolumn{6}{|c|}{ Word-Color SOA $=0 \mathrm{msec}$} \\
\hline Aware & 2.75 & 1.75 & 4.0 & 6.0 & 58 \\
\hline Unaware & 2.0 & 2.75 & 1.75 & 3.0 & 38 \\
\hline \multicolumn{6}{|c|}{ Word - Color SOA $=400 \mathrm{msec}$} \\
\hline Aware & 1.8 & 2.4 & 0.8 & 2.0 & 35 \\
\hline Unaware & 2.2 & 2.4 & 2.0 & 1.4 & 40 \\
\hline
\end{tabular}

small tendency toward more errors when the Word-Color SOA was 0 msec. This is the opposite effect to that on latency.

\section{Discussion}

The results bear upon two issues. The first is the nature of Stroop-type effects, the second is the effectiveness itself of the masked words and the conflict of this with other results in the literature. Although the latter is the main concern of this paper, the more specific issue will be discussed first.

Given the results, it is hard to hold the view that the only source of interference or facilitation in Stroop tasks is at the stage of response. Certainly it is not at the stage of overt verbal response production, since subjects were unable to name the word stimuli in the subthreshold condition. It is of course conceivable that the manual responses in the present experiment were mediated by covert naming. Indeed it is plausible that interference, as opposed to facilitation, has to be accounted for at a lexical rather than semantic level. If a lexicon is separate from a semantic system, as in Morton's (1968) Logogen model, and if interactions are only at a semantic level, then one might expect any color words which do not compete for verbalization to facilitate dealing with colors, by virtue of semantic or associative priming. An aspect of the data which bears upon this is the influence of neutral words. In this experiment manual RTs were uninfluenced by the presence of neutral words as compared to the absence of a word. In versions of the Stroop task which require some verbal mediation, even irrelevant stimuli which have lexical representation (i.e., words) but are semantically unrelated to the task have a small but significant interfering effect (Morton, 1969). In this experiment the neutral words had no effect. It is tempting to propose that in the usual case the effect of unrelated lexical items is due to competition for output from the lexicon to a phonological buffer (e.g., a covert articulatory loop) which is prior to word production but which mediates other responses. In the present experiment, however the manual responses are mediated, it is 
hard to conceive that such a buffer is accessible by the subthreshold words. In terms of Morton's (1970) model the second, output, threshold on lexical entries is not reached. It would thus appear that at least some interactive effects in Stroop tasks occur at the level of semantic interpretation or specification. That is, the results support Seymour's (1975) separation of interactive effects at the level of the automatic semantic encoding of the stimulus from interactive effects at the level of intentional response selection.

The more important and central point about this experiment is that subthreshold stimulus presentation was effective for all subjects. In Experiment 1 subjects were asked to compare one stimulus with another of whose presence they were unaware. To compare two representations, at some point the code or status of those representations has to be the same. It is probable that in Experiment 1 the status of the representations of the masked word and the choice words were nonequivalent (if only in the availability of certain characteristics). A conscious comparison was in effect impossible. For those subjects who adopted the "passive" attitude, they may not have been actually basing their response upon a comparison operation but upon the influence of the first word. (E.g., by some process such as graphic or semantic priming, it affected the phenomenal experience of one of the probes or attracted attention to it.) Indeed Dixon (1971) has noted that a passive attitude is important for subliminal effects to manifest themselves. In Experiment 2 subjects were not asked to do anything which required the subjection of the representation of the masked stimuli to conscious control processes. Under these conditions, passive effects are observable in all subjects. As implied by Dixon (1971) and Posner and Snyder (1975), the most effective way to investigate nonconscious representations is to look at their influence rather than to require subjects to utilize the representations selectively.

The third interesting aspect of Experiment 3 is its success. What has been shown is that words have been analyzed to a lexical if not semantic level without awareness. Without discussing the notion of threshold, this seems to constitute an example of subliminal perception. It is of particular note that Severance and Dyer (1973) failed to obtain subliminal Stroop effects in a procedure that in some respects seems more likely to produce them, ${ }^{2}$ since the Word-Color SOA, while substantial, was shorter and

\footnotetext{
${ }^{2}$ Severance and Dyer's method required subjects to name the color of a row of Xs appearing in red, blue, or green. Seventy-five milliseconds before their onset. interference stimuli came on. The words RED, BLUE, or GREEN or a series of Vs were used, a situation producing strong interference (Dyer \& Severance, 1973). These stimuli were rendered subliminal, on a prior session, by reducing their exposure duration until they could be named at no better than chance level. The subrecognition exposure durations thus determined ranged from 0.53 to $1.65 \mathrm{msec}$. The luminances for these stimuli, for the following blank field of $70+\mathrm{msec}$ and for the colors to be named were equated at 21 footlambert. Under these conditions there were no effects of the interfering stimuli.
} 
the response was naming. The crucial difference appears to be in the manner in which stimuli were rendered subliminal. Here pattern masking was used; in Severance and Dyer's study stimulus exposure was reduced to extremely small values before a blank field of equal luminance. Thus the energy in the field containing the interfering stimuli was lower than that in the field following it. According to Turvey (1973) this conforms to Peripheral or Energy masking. Turvey argues that Energy masking occurs at a more peripheral stage than pattern masking. It is thus conceivable that the difference between Severance and Dyer's procedure and the present one lies in the fact that, while both procedures render the stimulus unreportable, theirs does so because the contour information is degraded before it can be graphically analyzed whereas the present procedure of pattern masking operates at a later stage than that. Experiment 4 was performed to test this notion.

\section{EXPERIMENT 4}

Experiments 1 and 3, contrary to most recent accounts of visual masking, seem to imply that a word which is backward pattern masked such that it is not only unreportable but also undetectable, nevertheless gains access to a lexical or semantic representation. Severance and Dyer failed to find evidence for such access under exposure conditions which approximate to Turvey's description of Energy masking. A direct comparison of the two types of masking would serve to both illuminate the conditions under which subliminal Stroop, indeed lexical access, can be obtained and also further specify possible differences between the two types of masking.

To test the differences between the two types of masking it is necessary to ensure that one really is using functionally distinct procedures. Thus merely to use a contour mask and a blank field or a visual noise field is insufficient, since a pattern mask may operate by Energy if the energy and time relations between target and mask are appropriate (cf. 'Turvey, 1973, Experiment XVIII). Several characteristics distinguish Peripheral and Central Masking. Central Masking can only be obtained with a contour pattern, can only be obtained effectively by the mask following the target (backward masking), is possible both monoptically and dichoptically, and is characterized by an onset-onset function. Peripheral masking is obtainable with a blank field, a noise field, or a contoured field, works in both forward and backward directions, cannot be obtained dichoptically, and is characterized by an energy function.

The most direct way of testing the explanation of the difference between Severance and Dyer's and the present results would be to repeat the experiment rendering the word stimuli undetectable by techniques corresponding separately to central and peripheral masking. A secure method of ensuring their distinctness is to use a noise field monoptically 
and a pattern mask dichoptically. Given that the most conveniently available apparatus was an Electronic Developments 3-Field Tachistoscope, the only way of controlling which eye receives a stimulus was by means of pairs of crossed and uncrossed polaroid filters. However, polaroid filters would distort perception of color patches and might lead to unfortunate effects in a task involving color-based responses. Since it was possible to carry out monoptic and dichoptic masking and felt to be important, another task was employed.

From the point of view of interpreting Experiment 3 the important point was to have a method of assessing whether stimulus words were affecting performance by virtue of accessing a lexical or semantic representation under different conditions. This assessment is possible, in a fashion comparable to the Stroop task, by utilizing the Lexical Decision Task. This requires speeded classification of a letter string as a word or not. Meyer has shown that if two words are presented successively, then an associative, if not semantic, relation between them affects RT to the second (Meyer, Schvaneveldt, \& Ruddy, 1972; Schvaneveldt \& Meyer, 1973). Thus BUTTER is typically classified as a word faster if it follows BREAD than if it follows NURSE. This facilitation varies inversely in size with the time interval between stimuli and is not eliminated by an intervening unassociated word or nonword (Davelaar \& Coltheart, 1975). For this effect to occur the first word must have reached a lexical if not semantic representation. This task is in principle simpler to administer than the Stroop task, but allows comparable interpretation of effects under masking conditions. It also allows one to use polaroids with less fear of crucial stimulus distortion.

\section{Method}

Subjects. The subjects were 12 undergraduates at the University of Sussex.

Stimuli. Examples of the stimuli are shown in Table 5. They consisted of letter strings which were either words or nonwords. They were drawn from the stimuli used by Meyer and

TABLE 5

Examples of Pairs of Letter Strings Used in Lexical Decision Task

\begin{tabular}{|c|c|c|c|}
\hline Type of pair & Letter String 1 & Letter String 2 & No. of trials \\
\hline & (No response) & (RT Word/Nonword) & \\
\hline Nonword-Nonword & WOOT & GLAYER & 45 \\
\hline Word-Nonword & STREET & GLAYER & 45 \\
\hline Nonword-Word & WOOT & INFANT & 30 \\
\hline $\begin{array}{l}\text { Word-Word } \\
\quad \text { (unassociated) }\end{array}$ & STREET & INFANT & 30 \\
\hline $\begin{array}{l}\text { Word-Word } \\
\text { (associated) }\end{array}$ & CHILD & INFANT & 30 \\
\hline
\end{tabular}


Schvaneveldt (1971) where their generation and characteristics are fully described. They were grouped into sets of pairs for successive presentation of Nonword-Nonword, Word-Nonword, Nonword-Word, and Word-Word. The number of experimental pairs of each type is shown in Table 5. Thirty-six extra pairs were used for practice trials distributed in the same proportions as the experimental pairs.

The letter strings were drawn on 6 by 4 -in. white cards using a UNO stencil No. 2.101, as in Experiment 1. The pattern mask used in that experiment was also used. A random noise mask was used for peripheral masking. It was the same as that described by Laner, Morris, and Oldfield (1957) of 80 units per sq $\mathrm{cm}$. The noise pattern was $4 \mathrm{in}$. wide by $2 \mathrm{in}$. high.

\section{Apparatus and Exposure Conditions}

Stimuli were presented in an Electronic Developments 3-Field Tachistoscope. This was adapted by putting polaroid filters across two of the fields. The subject wore spectacles made of Perspex which were attached to the tachistoscope face shield and had earpieces. These spectacle frames held in front of each eye a piece of polaroid filter whose orientation could be altered. By these means it was possible to control which eye received the stimuli on each of the filtered tachistoscope fields. In accordance with Turvey's procedure the mask field was always received by the dominant eye. This was determined for each subject by binocular and monocular alignment of the index finger with a further stimulus. The illumination of the mask field was adjusted to yield a luminance of 16 footlambert, and it was always exposed for $20 \mathrm{msec}$. The other fields were adjusted to yield luminances of 10 footlambert.

Prior to the experimental trials proper, subthreshold SOAs were individually determined separately for dichoptic pattern masking and monoptic noise masking. The same procedure of presence-absence judgments was used as in Experiment 3 to find the first SOA at which subjects could not perform at greater than $60 \%$ correct, except that that SOA was the one used, without further reduction, for experimental trials. The other difference was in the exposure of the target field. This was always exposed for $10 \mathrm{msec}$ maximum and followed by a dark field before the mask field. When followed by the noise mask it was presented to the same, dominant eye; when followed by the pattern mask it was presented to the other, nondominant eye.

In the experimental session proper the first letter string was either masked by noise monoptically at the appropriate SOA, or by pattern dichoptically at the appropriate SOA, or presented for $500 \mathrm{msec}$ to the dominant eye with no mask following it. A dark field then followed until the onset of the second letter string, which occurred $2 \mathrm{sec}$ after the onset of the first letter string. The second letter string was exposed for $500 \mathrm{msec}$ in the third tachistoscope field with no polaroid and was therefore received binocularly. The exposure patterns for the three conditions of masking are illustrated in Fig. 3.

\section{Procedure}

For the purposes of the present experiment the usual procedure of carrying out the lexical decision task was slightly altered. Since subjects could not detect the first letter string anyway in the masked conditions they were not required to respond to it in the unmasked conditions. There was also no fixation field. They were thus instructed to use the first thing they saw as a temporal and locational cue for the second letter string to which they had to make a lexical decision. However, to ensure that they were looking at the correct place, subjects were asked to say "Ready" before each trial when they were looking at the center of the screen. The experimenter then initiated a trial with a switch which gave a click 1 sec before the first letter string was exposed. In response to the second letter string, subjects pressed a button with the index finger of their dominant hand for "Word" and another button with their index finger for "Nonword."

Subjects were tested on the three masking conditions on 3 separate days, two subjects in 
Unmasked

Dom Eye

Non-Dom Eye

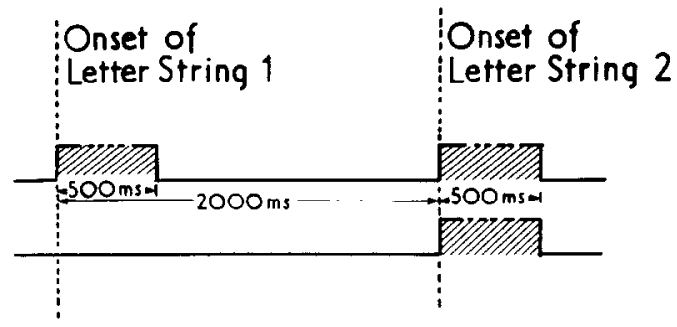

Centrally masked

Dom Eye

Non-Dom Eye

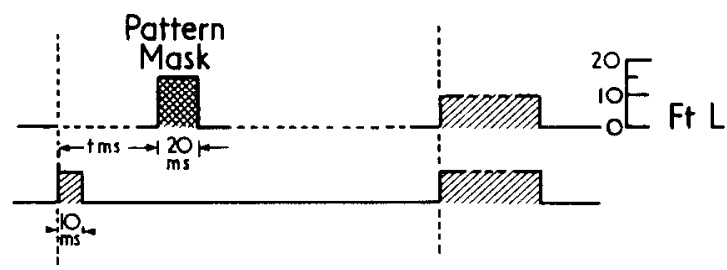

Peripherally masked

Dom Eye

Non-Dom Eye

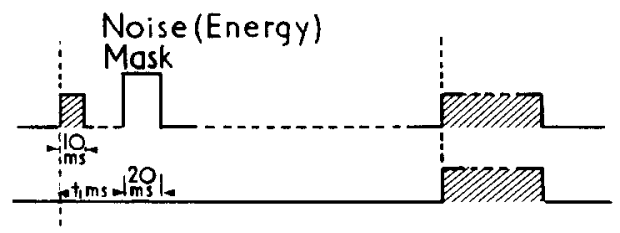

Fig. 3. Temporal and ocular arrangement of events in the three masking conditions of the lexical decision task.

each of the six possible orders. Before and after cach of the masked conditions, 40 trials of presence-absence judgments were given at the predetermined SOA for that condition. The critical SOA was not found to be too great in any case. Immediately before the test trials, 36 practice trials were given. The test trials were then given in two blocks of 90 trials, with a 2 -min rest interval. The practice trials were used to encourage the subject to respond as fast as possible without making errors.

Within the test sessions the order of trials was randomized separately for each subject, but the same stimuli were used for each masking condition.

\section{Results}

The overall error rate was beneath $3 \%$ for all subjects, and did not differ according to conditions.

The mean correct RTs for associated words and unassociated words under the three masking conditions are shown in Table 6.

In the Unmasked condition, RT to the second letter string averaged 62 $\mathrm{msec}$ faster when it was an associate of a prior word than when it was not $(F(1,11)=24.2, p<.001)$. In the Central Masking condition the average advantage of association was $56 \mathrm{msec}(F(1,11)=21.6, p<.001)$. With Peripheral masking the average effect of association, $4 \mathrm{msec}$, was not significant $(F(1,11)=.9)$. This difference in the association effect be- 
TABLE 6

Mean Positive RT (msec) to 2nd Letter String when Both Letter Strings Were Words

\begin{tabular}{cccc}
\hline 1st Letter String & Unmasked & $\begin{array}{c}\text { "Centrally" } \\
\text { Masked }\end{array}$ & $\begin{array}{c}\text { "Peripherally" } \\
\text { Masked }\end{array}$ \\
\hline 2nd Letter String & & & \\
Unassociated & 590 & 597 & 586 \\
Associated & 528 & 541 & 582 \\
\hline
\end{tabular}

tween central and peripheral masking was true for all subjects. That is, while no subject was aware of the first letter string under either masking condition, all subjects showed a substantial advantage for associated words when the first was centrally masked while none did when it was peripherally masked.

\section{Discussion}

The results support the explanation offered above of the difference between the present Experiment 3 and Severance and Dyer's findings. That is, energy masking impoverishes stimulus information prior to analysis of contour or figural properties, precluding pattern recognition of any kind, be it graphemic/lexical, object/scenic or otherwise; pattern masking operates after such analysis, but not on the results of that analysis which serve as data for further analyses. Experiment 4, then, has two important implications. Firstly it both qualifies and extends Turvey's (1973) distinction between Peripheral and Central Masking. Energy masking does appear to operate at a psychologically, not merely anatomically, more peripheral stage than Pattern masking, since it precludes that lexical/semantic access which pattern masking apparently allows. However, those very effects which allow us to make this distinction falsify the claim that central, pattern masking affects processes of pattern recognition themselves. The second implication of Experiment 4 is that when stimuli are rendered "subliminal," the procedure and conditions by which a detection threshold is determined and defined is crucial. That is, one is unlikely to obtain effects of nonconscious stimulation if the procedure for preventing awareness also renders figural properties of the stimulus inadequate (e.g., in terms of contrast) at anything like an optical level. This creates an interpretive problem for those studies of subliminal perception whose procedures amount to either peripheral masking or rendering the stimuli physically inadequate. What we now know about masking makes pre- and postexposure fields crucial in assessing the effects of manipulation of exposure duration alone. This post hoc criticism is made with the benefit of hindsight and in no way impugns the original research- 
ers or Dixon's (1971) discussion. However, it does argue for caution in assessing the validity of those studies which employed energy reduction procedures to achieve subliminality. Indeed, since metacontrast (as defined by Breitmeyer \& Ganz, 1976, i.e., where target and mask share figural properties but do not overlap on spatial coordinates) is not as yet completely understood in terms of its relation to the distinctions between peripheral and central and energy and pattern, even those studies using metacontrast require some caution in their interpretation.

\section{EXPERIMENT 5}

The results of Experiments 3 and 4 suggest that pattern masking interferes with phenomenal representation, or at least subjective confidence in phenomenal representation, while not affecting the automatic pattern analysis of the masked stimulus. This raises two related issues. First, what is the nature of the representation(s) left intact by pattern masking? Second, how does that representation relate to its conscious experience? That is, does the mask operate on that information which serves as data for other processes or on a separate, parallel representation?

Experiment 5 attempts to tackle one aspect of this issue. Both Morton $(1968,1979 a)$ and Shallice (1972) treat conscious awareness as criterially dependent on a threshold amount of activation accumulated in categorization units of particular stages of perceptual processing. Thus awareness is conceived of as quantitatively dependent on the amount of information in those systems which themselves nonconsciously mediate recognition of words or objects, and not as qualitatively dependent on information in a representational system specific to consciousness. If perceptual activation is the accumulation of that information which mediates priming, then it might well summate over repetitions. Further, if awareness is dependent on the degree of that same activation, then repetition of "subthreshold" information might well provide the accumulation necessary for phenomenal representation and thus detection responses.

Dixon (1971) has discussed a body of studies which purport to show the semantic effects of nonconscious stimuli upon speech content. This indeed was the initial interpretation of the observation which prompted the present studies. Lexical models such as Morton's (1968) attempt to deal with just such effects. But it is obviously of interest to explore the effects of repetition of nonconscious stimuli on speech content. Firstly, activation models such as Morton's predict that increasing activation in a particular lexical entry should increase the probability of semantic association in subsequent speech by priming the lexical choice. But, secondly it would be of interest to know the relationship of any such semantically associated responses to the probability of awareness and detection. Experiment 5 was designed to investigate these issues. 


\section{Method}

Subjects. Ten undergraduates and postgraduates served as paid subjects.

\section{Design}

The object of the experiment was to assess the effect of repetitions of masked words on (a) the association effect and (b) the probability of detection and attempts to report the word. Thus a word or blank field followed by a pattern mask was repeated a varying number of times. After the last repetition subjects either (a) had to make a lexical decision, where word stimuli were either associated or not with the masked word, if one had been presented, or (b) had to make a judgment as to whether a word or nothing had been presented before the mask. On all presence/absence trials they were also asked to try to guess a word that might have been presented.

\section{Apparatus}

An Electronic Developments 3-Field Tachistoscope was used to display the stimuli. Timing and control of repetitions was controlled by a combination of the four timers built into the Tachistoscope and an additional timer and adjustable counter to control number of repetitions of the test-field-plus-mask cycle. The last two were purpose-built and fitted for the experiment. A signal generator was used to produce an auditory warning signal (tone) after the last repetition before the lexical decision and presence/absence judgment tasks. Onset of the field which presented letter strings for lexical decision initiated a timer. It was terminated by the subject's response. Subjects responded with one of two buttons held in each hand.

\section{Procedure}

Subjects performed in two sessions, one where the Repetition Interval was $500 \mathrm{msec}$, one where it was $1000 \mathrm{msec}$. Before each session, each subject's critical SOA was determined as in the preceding experiments. Fifty trials of presence/absence judgments were also given after a session was completed to ensure that subjects' critical SOAs had not lowered. In no case was there a significant shift in percent correct presence/absence judgments from before to after the test trials.

The experimental procedure is illustrated in Fig. 4 and was as follows. Before each trial the subject was told whether he would have to make a lexical decision or presence/absence judgment. However, they were not able to ignore the repetition sequence on lexical decision trials, since they did not know the number of repetitions or when the letter string would appear until the tone warning signal. The experimenter said "Ready?" before each trial and when the subject responded "Yes" initiated the trial. The stimulus field was either a word or a blank white field and lasted for $10 \mathrm{msec}$. The mask field followed a black field after the duration determined for that subject and lasted for $30 \mathrm{msec}$. This sequence was repeated either 1, 2, 4, 8, 12, 16, or 20 times with an Interrepetition Interval of $500 \mathrm{msec}$ in one session and $1000 \mathrm{msec}$ in the other session. Five hundred milliseconds after the offset of the last repetition of the mask, a signal was generated, which was a $1000 \mathrm{~Hz}$ tone of $50 \mathrm{~dB}$, and lasted $100 \mathrm{msec}$. Five hundred milliseconds after its onset either a single letter string appeared or the words "present-absent." This lasted for $1000 \mathrm{msec}$. Subjects' reaction times were shown on a Dawes Timer and recorded by the experimenter. All stimuli were drawn on the center of the cards as in the previous experiments. All stimulus fields were 10 footlambert luminance. Subjects were asked to respond as quickly and accurately as possible on lexical decision trials. On presence-absence trials, after the subject had responded he or she was asked to guess a word that might have appeared before the mask. The prime purpose was to assess whether repetition of the masked word affected their responses, compared to the 


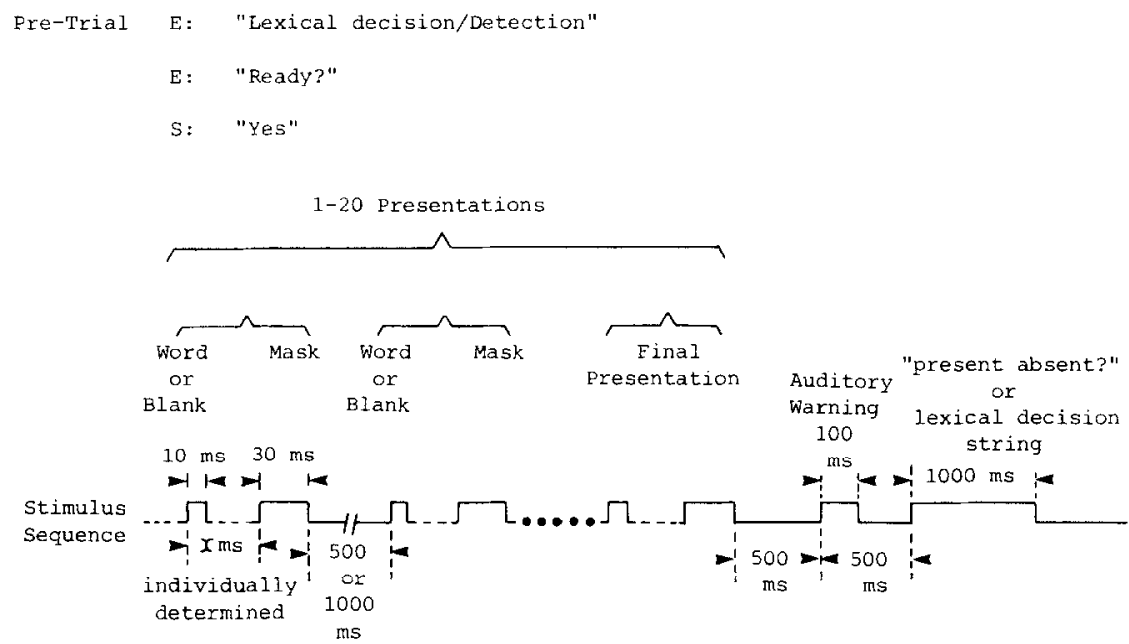

Fig. 4. Order of events and temporal arrangement on a single trial of Experiment 5. Four aspects were varied: (a) word or blank before mask; (b) no. of repetitions of masked field; (c) interrepetition interval; (d) nature of task: detection/lexical decision.

blank field. Therefore they were not asked to do this on lexical decision trials, since the lexical decision string, when it was a word, might have influenced their response.

For each number of repetitions, 40 trials of presence-absence judgments and 40 trials of lexical decision were given, yielding 560 trials in all. Order of number of repetitions was randomized over trials. Trials were given in blocks of 40 . After each 80 trials any incorrect lexical decision trials were repeated and the subject was given a break of about $4 \mathrm{~min}$. Each suhject nerformed the two sessions with different Interrepetition Interval (IRI) about a week apart. Order of the two sessions was balanced over subjects. Before each test session subjects were given 60 practice trials, with 30 of each type of decision, randomized in their order.

Stimuli. The stimuli used for the presence-absence judgments were taken from a sample of 200 medium- to high-frequency words of four to eight letters in length (Kucera \& Francis, 1967; Thorndike \& Lorge, 1944). The words in the lexical decision task were taken from Meyer's lists and Postman and Keppel's (1970) word association norms. Nonwords were letter strings exhibiting the same range of number of letters and while all obeyed the rules of English orthography, none were homophonic with English words. For each number of repetitions, each word was presented twice for lexical decision, once preceded by a word with which it was associated, once preceded by a word with which it was not associated. These two trials were always separated by at least 80 other trials.

\section{Results}

Table 7 shows correct positive lexical decision times to words which were associated with what had preceded the mask and to words which were not. There was no effect of number of repetitions on RTs to unassociated words. Since what is of interest here is the association effect, all further analyses were carried out on RT to associated words subtracted from that to unassociated words, rather than on raw latencies. 
TABLE 7

Mean Correct Positive Lexical Decision Times as a Function of Repetitions of the Masked Word

\begin{tabular}{clccccccc}
\hline & & \multicolumn{7}{c}{ Number of repetitions } \\
\cline { 3 - 8 } $\begin{array}{c}\text { Interrepetition } \\
\text { interval (msec) }\end{array}$ & Association & 1 & 2 & 4 & 8 & 12 & 16 & 20 \\
\hline \multirow{2}{*}{500} & Unassociated & 567 & 564 & 559 & 561 & 558 & 562 & 556 \\
& Associated & 518 & 508 & 491 & 483 & 475 & 479 & 469 \\
\multirow{2}{*}{1000} & Unassociated & 562 & 563 & 556 & 560 & 557 & 554 & 553 \\
& Associated & 524 & 521 & 508 & 502 & 494 & 488 & 485 \\
\hline
\end{tabular}

Figure 5 shows for each number of repetitions (a) the probability of correct detection (presence-absence judgments) and (b) the size of the association effect ([mean RT unassociated] - [mean RT associated]). Separate analyses of variance for each IRI were carried out on the probability of correct presence-absence judgments according to number of repetitions. In neither case was there any significant effect. An overall

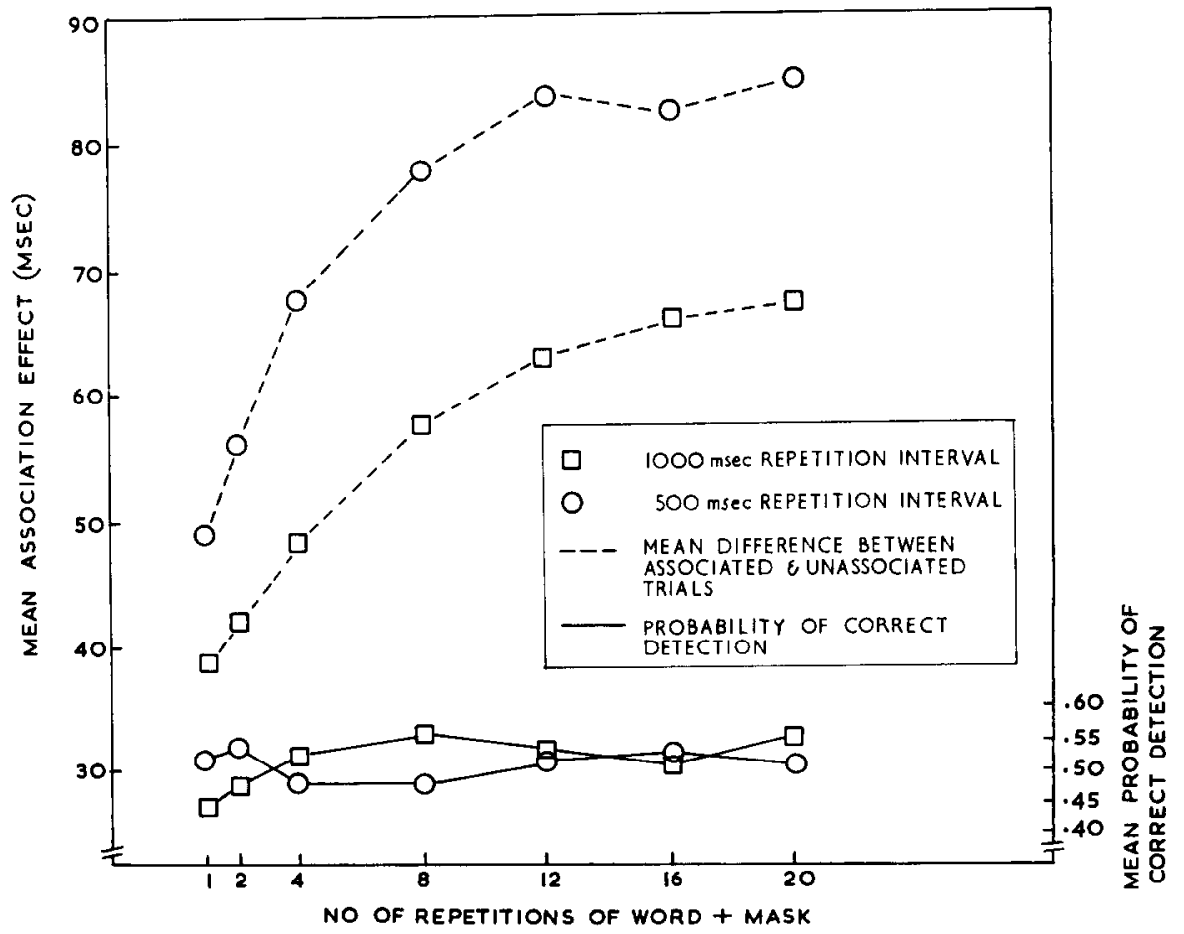

FIG. 5. Effect of number of repetitions of word-plus-mask at two different repetition intervals on (a) size of the association effect in subsequent lexical decision, and (b) presence-absence judgments. 
analysis of variance was carried out on the size of the association effect with IRI and number of repetitions as factors. There was a highly significant effect of number of repetitions $(F(6,54)=225.57, p<.001)$, as there also was for IRI $(F(1,9)=39.76, p<.001)$. These two factors also interacted significantly $(F(6,54)=2.94, p<.05)$.

In order to investigate the quantitative relationship between association effect and the number of repetitions, separate one-factor analyses of variance were carried out on the association effects for the 500-msec and 1000 -msec IRIs. The variance attributed to the differences in number of repetitions was partitioned into linear and nonlinear components. For 500 -msec IRI, the effect of number repetitions was significant $(F(6,54)=$ $94.34, p<.001)$. The linear and nonlinear components were both significant (linear: $F(1,54)=469.46, p<.001$; nonlinear: $F(5,54)=19.31, p<$ $.001)$. For 1000-msec IRI, the effect of number of repetitions was significant $(F(6,54)=106.17, p<.001)$. The linear and nonlinear components were also both significant (linear: $F(1,54)=600.64, p<.001$; nonlinear: $F$ $(5,54)=7.27, p<.001)$. The slopes of the linear components were 1.83 $\mathrm{msec} /$ repetition for $500-\mathrm{msec}$ IRI, and $2.55 \mathrm{msec} /$ repetition for $1000-\mathrm{msec}$ IRI. Since in both cases there were significant nonlinear components it is difficult to compare the "slopes" of the curves for the different IRI values. However, the interaction of IRI and number of repetitions indicates some difference. Inspection of the graph leads one to believe that with 1000-msec IRI, repetition has less effect than with 500-msec IRI but continues to have an effect over a larger number of repetitions. That is, with 500 -msec IRI the effect asymptotes sooner than with 1000 -msec IRI.

The third aspect of the data was the effect of repetition on verbal identification. Initially subjects were all loath to guess a word. However, they were all induced to do so after a few of the practice trials. In only three cases did subjects actually guess the word which had preceded the mask. Two of these were with eight repetitions at 500-msec IRI and one with 16 repetitions at 1000 -msec IRI. In order to assess whether there was any effect upon the semantic association of guessed words to repeated masked words, the following was done. For all repetition values, each masked word together with the word reported for it was written on a card. These cards were then given to three independent judges who knew nothing of the experiment. For each card, judges decided whether the two words were associated in meaning or not. The three sets of judgments were collected and for each card those judgments agreeing by at least two out of three were marked down. The numbers of pairs rated as associated per number of repetitions for each subject was subjected to a Monotonic Trend Analysis for Correlated Data (Ferguson, 1965). No significant effect of number of repetitions on semantic relation of guessed word to masked word was found either for 500-msec IRI $(z=1.02)$ or for 1000- 
msec IRI $(z=1.31)$. In fact the highest probability of association at any one number of repetitions was .8 , which falls within Ellis and Marshall's (1978) estimates of chance association.

\section{Discussion}

The association effect. Repetition of a masked word led to a monotonic increase in the size of the association effect which seems to asymptote, earlier with an IRI of $500 \mathrm{msec}$ than with one of $1000 \mathrm{msec}$. Since lexical decision time to nonassociated words showed no systematic effect of repetition, the repetition effect is due to the lowering of RT to associated words. The effect of repetition could be due to one of two things. It might be due to a build-up of activation in the lexical entry of the lexical decision word by virtue of its association to the repeated word. On the other hand the decrease in mean RT to associated words could be due to an increased probability with repetition that any associative priming takes place in an all-or-none fashion. This second hypothesis does not assume that the increased lowering of RT to associated words reflects greater activation, only that a greater proportion of trials with a lowered RT contribute to the mean as a function of repetition. Thus the nonlinear components of the curves would reflect logarithmic rates of the probability of an association effect with number of repetitions. However, if this were the case, one would expect that the variance of RTs on associated trials would be greater than on unassociated trials and that this variance would decrease with repetition. Although the variance of associated RTs does decrease slightly with repetition, the initial variance (with one and two repetitions) is no greater than on unassociated trials, indeed is (nonsignificantly) smaller. The second hypothesis then is best rejected.

If the repetition effect is therefore due to a build-up of activation by associative priming, how should the effect of IRI be interpreted? The effect of repetition is greater with the shorter IRI (the steeper initial slope) but the effect seems to asymptote sooner. The greater initial effect can most conveniently be accounted for in terms of decay of activation. Suppose, most simply, that every time a lexical entry or memory location is accessed a constant amount of priming is added to lexical entries associated, with a particular "distance" or "strength," to the source location. Suppose also that activation decays at a constant rate or even at a rate proportional to the level of activation. These two assumptions predict that with longer IRIs, within the bounds of monotonic decay the total amount of associative activation will increase more slowly with repetition. Why does the increase in size of association effect asymptote sooner with the shorter IRI (inferred from (a) inspection, and (b) the greater nonlinear component)? Four types of hypothesis present themselves. (a) There is a maximum level of activation. This is approached sooner with a 
faster build-up, i.e., with the shorter IRI. (b) The amount of activation donated by each repetition is inversely proportional to the level of activation to which it is added. (c) Activation generates inhibition either proportional to itself or once a certain level has been reached. These last two alternatives are explanatory variants of Hypotheses (b) and (a), respectively. (d) Decision times to associates asymptotes as it reaches a minimum possible RT for that type of decision. Given the data it is difficult to distinguish these hypotheses. In any case the issue is peripheral to the central concerns of the experiment. However, the main point is that nonconscious priming is cumulative but has bounds.

Detection and report. Repetition had no effect on the probability of detection. Nor did it appear to affect the semantics of a word the subject was forced to guess. It is of particular note that detection and report remained unaffected by repetition when number of repetitions appeared to have had a maximum effect on size of the association effect and had apparently ceased to have further semantic effects. It is thus hard to argue that the effect of masking is merely upon the amount of stimulus information necessary for detection. Haber (1967) reports experiments where repeated brief exposures of a word, not masked, led to growth of the percept in terms of accuracy of report. But in those cases the subjects were never in doubt as to the presence of the word, and could use each presentation to intentionally and strategically sample different locations. It is clear that within the bounds of the present experiment, detectability or awareness could not be built up. It is possible that the lower IRI of 500 msec was too long, in that whatever "subliminal" sensory representation there might be, it decays in less than that time. But even if this is so, the implication of the dissociation between the effect of repetition on lexical/ semantic representation and on awareness is that these are qualitatively different. Suppose that judgments of presence or a stimulus event are based on some sensory record of that event which is destroyed or made totally unavailable by a pattern mask at low enough SOAs. Then no amount of repetition will produce awareness if that record is destroyed on each presentation before it can be utilized. To this extent the difference between awareness and nonawareness is a qualitative one and not merely based on strength, amount of information, or amount of activation-either the record is criterially available or it is not.

This is a quite different conception from that of Shallice (1972) and Morton (1970, 1979a). Both of these authors conceive of access to consciousness as being purely a matter of the strength or activation in those information processing units which also mediate access to meaning. While they both acknowledge in their theoretical conceptualizations that semantic and associative effects can be achieved before awareness, they nevertheless see awareness as requiring "more of the same." Thus Mor- 
ton proposes that a "logogen" receives sensory information regarding a morpheme. When enough information has accumulated to pass a first threshold, the semantics of that morpheme are activated; when enough further information, presumably of the same type, has accumulated to pass a second threshold, the morpheme or word enters consciousness and becomes available as a response. ${ }^{3}$ However, the nature of logogensensitive information remains unspecified. Shallice's (1972) position can for present purposes be mapped almost entirely onto this aspect of the logogen model. While the present experiment does not directly falsify these approaches, it does cast severe doubt on them. Repetition is clearly continuing to producc activation to a maximum at that representational stage mediating associative priming; yet it fails to produce enough activation by that point to affect either detection or response characteristics. Dixon's (1971) position is less clearly affected by the results, since he sees awareness being mediated by a different system (nonspecific activation) from that mediating representation of meaning (specific activation of dictionary units). However, while the importance of stimulus "energy" is not denied here, all positions which rely only on energy for awareness seem to be discredited. That is, in the present experiments neither energy (Experiment 4) nor accumulated activation (Experiment 5) appears to determine conscious versus nonconscious perception. At least this is so to the extent that the pattern-masking procedure employed here operates by SOA, in contrast to the energy-masking procedure, which does work by energy and fails to produce unconscious priming effects (see also Marcel, $1980 \mathrm{~b}$, for replication of this difference between the two forms of masking). Again many experiments aimed at producing subliminal perception reviewed by Dixon amount to an energy-masking procedure.

Repetition of a masked word also failed to affect the semantic nature of forced guesses. Of course this null effect may be due to the insensitivity of the measure. That is, since subjects are unaware of the masked word, their guesses may be determined more by what they are aware of or by their last utterance than by the masked word. Thus the semantic activation produced by the masked word may be weak relative to other determinants of lexical selection. This may well have been revealed if subjects had been asked to produce several guesses on each trial rather than only one. If this technique had been sufficiently sensitive then number of repetitions may well have affected either the probability of semantic association in each train of responses or its serial position.

\footnotetext{
${ }^{3}$ The assumed synonymity of awareness and availability of the specific stimulus as a speech response in Morton's model seems counterintuitive and is a further problem. There are many cases when someone is aware of the presence of an event but cannot recover its specific identity. Indeed it is this in combination with the Identity Assumption which has led to the conception of perceptual microgenesis as analytic.
} 
If, however, the null effect is genuine then other implications follow. It may be that lexical or semantic characteristics of stimulus words cannot be reflected in intentional output unless the input has been conscious. This conclusion, however, is not satisfactory. First, the literature on slips of the tongue (Fromkin, 1973; Motley \& Baars, 1976) suggests that semantic determinants outside of awareness do affect speech content, i.e., the reality of Freudian slips. Second, the literature reviewed by Dixon (1971, chap. 4) provides several instances of nonconscious determinants of responses at the semantic level. Even if the priming obtained in lexical decision is restricted to a lexical level, this alone does not account for the disparity in priming between lexical decision and output. One possible solution to the problem is to take the step taken by Marcel and Patterson (1978) and Morton (1979b), and propose that input and output lexicons are separate. One might then suppose that unless the input had been conscious or the output lexicon had been used, input would have little or no effect on output, even though it activates other entries in the input lexicon. While viable, this proposal must remain speculative in view of the limitations of the experiment.

To summarize the implications of Experiment 5, it does not appear that what pattern masking leaves intact is any component of what is commonly termed the Icon. While pattern masking leaves intact a representation which mediates an accumulation of lexical/semantic priming, it does not leave intact anything which mediates accumulation of what is required for awareness. A more radical speculation is that awareness is not a threshold phenomenon in any way susceptible to the accumulation of information used for other perceptual purposes, but depends qualitatively on the availability of a particular representation. Thus however strong is semantic activation it cannot of itself mediate awareness. Nor does externally derived lexical/semantic activation appear of itself to affect speech content.

\section{CONCLUDING COMMENTS}

This paper began by stating two paradigm assumptions underlying information-processing approaches. Given the results reported here, the Identity Assumption appears to be untenable. The microgenetic assumption of serial recoding is not directly weakened by the present studies. Indeed not only has the logic of the assumption been called on in interpreting each of the present experiments, but in a general sense it is necessarily true. However, particular forms of the microgenetic sequence insofar as they are inferred on the basis of the Identity Assumption from empirical studies, are invalidly inferred, though quite possibly correct.

Conclusions about the Identity Assumption depend on the present results and their validity. While Experiment 1 may be artifactual, Experi- 
ments 3, 4, and 5 do not appear to be so, ${ }^{4}$ and the latter three studies are more valid anyway in that they indirectly assess the representation of information. Should these studies be regarded as necessarily related to consciousness? One response to this is to propose that the presentation conditions referred to as nonconscious are merely a matter of the subject's criterion for reporting awareness. Perhaps so. But this is to advance a theory of what it is to be aware rather than to deny the present relevance of consciousness. Most important for deciding how to interpret the present findings is another study using the same techniques as reported here (Marcel, 1980b). That study compared the effects of polysemous words (PALM), when masked or not, on the processing of a subsequent word related to one of its meanings (WRIST). When it was not masked, PALM only facilitated processing of WRIST when itself preceded by HAND; when preceded by TREE, it delayed processing of WRIST, compared for example to CLOCK PALM WRIST. When it was masked, however, PALM facilitated processing of WRIST, irrespective of what preceded it. Effects that are qualitatively different but at least as strong suggest a qualitative difference in the state of the internal representation of the critical word. This encourages the view that the appropriate interpretation of the present experiments is indeed in terms of consciousness.

The most satisfactory account of the present experiments, then, is that pattern masking does not impede visual processing but rather impedes the availability to consciousness of what is masked. Discussion of how it does so and of what is involved in being conscious of an event is left to a theoretical paper which follows this. However, there are certain methodological implications which follow directly from the present experiments.

\section{Methodological Considerations}

There are several especially important points raised by the findings reported here. First, masking has been considered a particularly valuable

\footnotetext{
${ }^{4}$ Since this and the subsequent theoretical paper were originally written, various replications have been attempted. Experiments 1 and 4 have been successfully replicated by Fowler, Wolford, Slade and Tassinary (1981). While they were able to find a possible artifact in Experiment 1 they were unable to do so for Experiment 4. Experiment 3 has been replicated with almost identical latencies by Ellis (unpublished manuscript, University of Bangor, Wales). However, an attempt to replicate Experiment 4 by Creighton (unpublished data, Applied Psychology Unit, Cambridge) yielded very small and variable nonconscious priming effects, and an attempt by Evett (University of Bristol) was unsuccessful. The point of this is that the phenomena reported here may depend on experimental factors as yet unexplored. Chambers (Deakin University, Australia; manuscript in preparation) reports that dichoptic masking is critical. This is highly plausible, since it is the only way to ensure that pattern masking does not operate at a peripheral level at low SOAs.
} 
technique for revealing early stages of perceptual processing. As Haber (1969) pointed out it is the one technique whereby one can supposedly halt stimulus processing at a certain stage without relying on the subject's ability to address him/herself to that stage and remain uncontaminated by any further automatic processing. Masking can no longer be considered to fulfill this role, since it does not appear to impede such processing. Indeed our whole conception of what has been referred to as Iconic memory has to be reconsidered. This will be broached in the theoretical paper which follows. More generally what the present studies reveal to have been misleading in studies of masking, and indeed of early perceptual processing, is the response measure used, that of report. Report may reveal some aspects of conscious experience and its limits, but hardly anything of perceptual processes themselves. In fact, there is good reason to believe that it may be extremely misleading in several ways to rely on conscious percepts to tell us about perceptual processing. First the languages of representations derived at a nonconscious and a conscious level may be quite different, a point to be explored in the paper to follow. Second, as Nisbett and Wilson (1977) suggest, reports, even of tachistoscopic stimuli or of one's own sensations, probably tell us more about people's beliefs about sensation and cognition than about those processes themselves. Third, paying attention to stimuli, which is required by most studies involving report, may well induce a state quite inimical to revealing automatic nonconscious processes. That is, people attempt to base their behavior on notions of "rationality." If the task is normally one of reading or reporting, one does not report a word, even if it "comes to mind," if one is not conscious of having seen one. Further, paying attention to the outer world (i.e., to specific stimuli) or being prepared to act are likely to narrow one's attention and preclude awareness of what has only an inner source.

Psychologists have not realized what they are doing. Indeed, whenever they suspect that their studies are "contaminated" by "higher level" processes (postcategorical representations, beliefs, strategies), all too often their first response is to try to prevent their presence or influence. In fact, these "problems" present the most truly psychological issues and those domains worthy of infinitely more study than they are at present given.

However, how can perceptual processes themselves be studied at a psychological level? First, indirect rather than direct measures should be used. If we are interested in the processing of a stimulus at a certain level or in certain terms, without contamination of later coding or response processes, then we should look at its effects at that level or in those terms on the processing of another stimulus. The time course and structure of 
processing can be tapped by varying the time between the influencing and the to-be-influenced stimulus.

But perhaps even indirect measures are not enough. As suggested above, allowing an event to reach a state of conscious representation at all may produce misleading effects. Not only may different dimensions of coding obtain for conscious and nonconscious representations, but some of what is represented of an event prior to consciousness may be inhibited by that event's access to consciousness (see Marcel, 1980b). To the extent that an investigator is interested only in early nonconscious perceptual processes, it follows that consciousness of the relevant stimulus ought to be prevented by masking or some functionally equivalent procedure. It would at least be interesting to compare the results of direct measures involving conscious perception and indirect measures where consciousness is precluded. Experiments which approach this via unattended stimuli are open to criticisms of strategic sampling by the subject. In studies which rely only on inability to report, but not on inability to detect, subjects can always be said to have partial information available. Awareness itself needs manipulation.

\section{REFERENCES}

Allport, D. A. On knowing the meaning of words we are unable to report: The effects of visual masking. In S. Dornic (Ed.), Attention and performance. New York/London: Academic Press, 1977. Vol. 6.

Anderson, J. R., \& Bower, G. H. Human associative memory. Washington, D.C.: Winston, 1973.

Bousefield, W. A., Cohen, B. H., Whitmarsh, G. A., \& Kincaid, W. D. The Connecticut free associational norms. University of Connecticut, Studies on the Mediation of Verbal Behavior Technical Report No. 35, 1961.

Brand, J. Classification without identification in visual search. Quarterly Journal of Experimental Psychology, 1971, 23, 178-186.

Breitmeyer, B. G., \& Ganz, L. Implications of sustained and transient channels for theories of visual pattern masking, saccadic suppression and information processing. Psychological Review, 1976, 83, 1-36.

Coltheart, M., Patterson, K. E., \& Marshall, J. C. (Eds.) Deep dyslexia. London: Routledge \& Kegan Paul, 1980.

Corteen, R. S., \& Wood, B. Autonomic responses to shock-associated words in an unattended channel. Journal of Experimental Psychology, 1972, 94, 308-313.

Craik, F. I. M., \& Lockhart, R. S. Levels of processing: A framework for memory research. Journal of Verbal Learning and Verbal Behavior, 1972, 11, 671-684.

Davelaar, E., \& Coltheart, M. Effects of interpolated items on the association effect in lexical decision tasks. Bulletin of the Psychonomic Society, 1975, 6, 269-272.

Dixon, N. F. Subliminal perception: The nature of a controversy. London: McGraw-Hill, 1971.

Dyer, F. N., \& Severance, L. J. Stroop interference with successive presentations of separate incongruent words and colors. Journal of Experimental Psychology, 1973, 98, $438-439$. 
Ellis, A. W., \& Marshall, J. C. Semantic errors or statistical flukes? A note on Allport's "On knowing the meaning of words we are unable to report." Quarterly Journal of Experimental Psychology, 1978, 30, 569-575.

Ferguson, G. A. Nonparametric trend analysis. Montreal: McGill Univ. Press, 1965.

Fowler, C. A., Wolford, G., Slade, R., \& Tassinary, L. Lexical access with and without awareness. Journal of Experimental Psychology: General, 1981, 110, 341-362.

Fox, J. Continuity, concealment and visual attention. In G. Underwood (Ed.), Strategies of information processing. New York/London: Academic Press, 1978.

Fromkin, V. A. (Ed.) Speech errors as linguistic evidence. The Hague: Mouton, 1973.

Gibson, J. J. The perception of the visual world. Boston: Houghton-Mifflin, 1950.

Gibson, J. J. The senses considered as perceptual systems. Boston: Houghton-Mifflin, 1966.

Goldstein, K. Language and language disturbances. New York: Grune \& Stratton, 1948.

Haber, R. N. Repetition as a determinant of perceptual recognition processes. In W. Wathen-Dunn, J. Mott-Smith, H. Blum, \& P. Lieberman (Eds.), Models for the perception of speech and visual form. Cambridge, MA: MIT Press, 1967.

Haber, R. N. Introduction to R. N. Haber (Ed.), Information processing approaches to visual perception. New York: Holt, Rinehart \& Winston, 1969.

Humphrey, N. K. Seeing and nothingness. New Scientist, 1972, 30th March, 682-684.

Ingling, N. Categorization: A mechanism for rapid information processing. Journal of Experimental Psychology, 1972, 94, 239-243.

Keele, S. W. Attention demands of memory retrieval. Journal of Experimental Psychology, $1972,93,245-248$.

Kucera, H., \& Francis, W. N. Computational analysis of present-day American English. Providence, RI: Brown Univ. Press, 1967.

Kuhn, T. S. The structure of scientific revolutions. Chicago: Univ. of Chicago Press, 1970.

Laner, S., Morris, P., Oldfield, R. C. A random pattern screen. Quarterly Journal of Experimental Psychology, 1957, 9, 105-108.

Lewis, J. L. Semantic processing of unattended messages under dichotic listening. Journal of Experimental Psychology, 1970, 85, 225-228.

Mackay, D. G. Aspects of the theory of comprehension, memory and attention. Quarterly Journal of Experimental Psychology, 1973, 25, 22-40.

Marcel, A. J. Conscious and unconscious perception: Word recognition, visual masking and an approach to consciousness. Unpublished manuscript, University of Reading, 1980(a).

Marcel, A. J. Conscious and preconscious recognition of polysemous words: Locating the selective effects of prior verbal context. In K. S. Nickerson (Ed.), Attention and performance VIII, Hillsdale, NJ: Erlbaum, 1980(b).

Marcel, A. J., \& Forrin, B. Naming latency and the repetition of stimulus categories. Journal of Experimental Psychology, 1974, 103, 450-460.

Marcel, A. J., Katz, L., \& Smith, M. Laterality and reading proficiency. Neuropsychologia, $1974,12,131-139$.

Marcel, A. J., \& Patterson, K. E. Word recognition and production: Reciprocity in clinical and normal studies. In J. Requin (Ed.), Attention and performance. Hillsdale, NJ: Erlbaum, 1978. Vol. 7.

Marr, D. Early processing of visual information. Philosophical Transactions of the Royal Society, $B, 1976,275,483-524$.

Marshall, J. C., \& Newcombe, F. Patterns of paralexia: A psycholinguistic approach. Journal of Psycholinguistic Research, 1973, 2, 175- 199.

Meyer, D. E., \& Schvaneveldt, R. W. Facilitation in recognizing pairs of words: Evidence of a dependence between retrieval operations. Journal of Experimental Psychology, $1971,90,227-234$. 
Meyer, D. E., Schvaneveldt, R. W., \& Ruddy, M. G. Activation of lexical memory. Paper presented at the meeting of the Psychonomic Society, St. Louis, MI, November 1972.

Morton, J. Grammar and computation in language behavior. In J. C. Catford (Ed.), Studies in Language and Language Behaviour. Center for Research in Language and Language Behavior, Progress Report, No. VI, Ann Arbor: University of Michigan, 1968.

Morton, J. Categories of interference: Verbal mediation and conflict in card sorting. British Journal of Psychology, 1969, 60, 329-346.

Morton, J. A Functional Model for Memory. In D. A. Norman (Ed.), Models of memory. New York: Academic Press, 1970.

Morton, J. Word recognition. In J. Morton \& J. C. Marshall (Eds.), Psycholinguistic Series. London: Elek, 1979. Vol. 2. (a)

Morton, J. Some experiments on facilitation in word and picture recognition and their relevance for the evolution of a theoretical position. In P. A. Kolers, M. E. Wrolstad, \& H. Bouma (Eds.), Processing of visible language, I. New York: Plenum, 1979 (b).

Morton, J. Two auditory parallels to deep dyslexia. In M. Coltheart, K. E. Patterson, \& J. C. Marshall (Eds.), Deep dyslexia. London: Routledge \& Kegan Paul, 1980.

Morton, J., \& Chambers, S. M. Selective attention to words and colours. Quarterly Journal of Experimental Psychology, 1973, 25, 387-397.

Motley, M. T., \& Baars, B. J. Semantic bias effects on the outcomes of verbal slips. Cognition, 1976, 4, 177-187.

Nisbett, R. E., \& Wilson, T. De C. Telling more than we can know: Verbal reports on mental processes. Psychological Review, 1977, 84, 231-259.

Posner, M. I. Abstraction and the process of recognition. In G. H. Bower \& J. T. Spence (Eds.), The psychology of learning and motivation: Advances in research and theory. New York: Academic Press, 1969. Vol. 3.

Posner, M. I., \& Snyder, C. R. R. Attention and cognitive control. In R. L. Solso (Ed.), Information processing and cognition: The Loyola symposium. Hillsdale, NJ: Erlbaum, 1975.

Postman, L., \& Keppel, G. Norms of word association. New York/London: Academic Press, 1970.

Reicher, G. M. Perceptual recognition as a function of stimulus material. Journal of Experimental Psychology, 1969, 21, 275-280.

Schvaneveldt, R. W., \& Meyer, D. E. Retrieval and comparison processes in semantic memory. In S. Kornblum (Ed.), Attention and performance. New York: Academic Press, 1973. Vol. 4.

Severance, L. J., \& Dyer, F. N. Failure of subliminal word presentations to generate interference to color naming. Journal of Experimental Psychology, 1973, 101, 186-189.

Seymour, P. H. K. Semantic equivalence of verbal and pictorial displays. In A. Kennedy \& A. Wilkes (Eds.), Studies in long term memory. London: Wiley, 1975.

Shallice, T. Dual functions of consciousness. Psychological Review, 1972, 79, 383-393.

Shiffrin, R. M. The locus and role of attention in memory systems. In P. M. A. Rabbitt \& S. Dornic (Eds.), Attention and performance. New York: Academic Press, 1975. Vol. 5.

Sperling, G. Successive approximations to a model for short-term memory. Acta Psychologica, 1967, 27, 285-292.

Thorndike, E. L., \& Lorge, I. A teacher's word book of 30,000 words. New York Teachers College, Columbia University, 1944.

Turvey, M. T. On peripheral and central processes in vision: Inferences from an information-processing analysis of masking with patterned stimuli. Psychological Review, 1973, 80, 1-52.

Turvey, M. T. Perspectives in vision: Conception or perception? In D. Duane \& M. Rawson (Eds.), Reading, perception and language. Baltimore, MD: York, 1975.

von Wright, J. M., Anderson, K., \& Stenman, U. Generalization of conditioned GSR in 
dichotic listening. In P. M. A. Rabbitt (Ed.), Attention and performance. New York/ London: Academic Press, 1975. Vol. 5.

Weber, R-M. First graders' use of grammatical context in reading. In H. Levin \& J. P. Williams (Eds.), Basic studies on reading. New York: Basic Books, 1970.

Weiskrantz, L., Warrington, E. K., Sanders, M. D., \& Marshall, J. Visual capacity in the hemianopic field following a restricted occipital ablation. Brain, 1974, 97, 709-728.

Werner, H. Microgenesis and aphasia. Journal of Abnormal and Social Psychology, 1956, $52,347-353$.

Wheeler, D. D. Processes in word recognition. Cognitive Psychology, 1970, 1, 59-85.

Wickens, D. D. Characteristics of word encoding. In A. W. Melton \& E. Martin (Eds.), Coding processes in human memory. Washington, D.C.: Winston, 1972.

(Accepted December 2, 1982) 